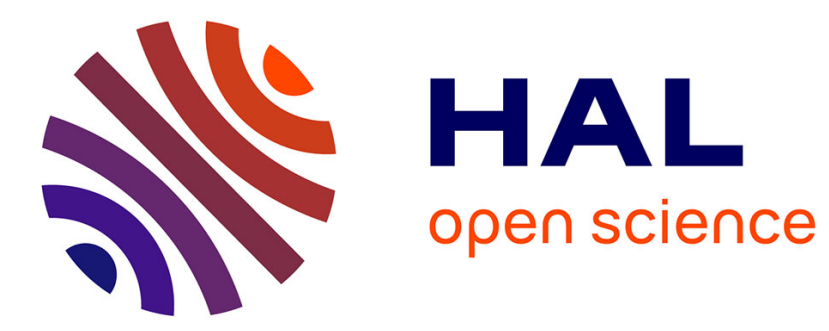

\title{
Seismic evidence for partial melt below tectonic plates
}

Eric Debayle, Thomas Bodin, Stéphanie Durand, Yanick Ricard

\section{To cite this version:}

Eric Debayle, Thomas Bodin, Stéphanie Durand, Yanick Ricard. Seismic evidence for partial melt below tectonic plates. Nature, 2020, 586 (7830), pp.555-559. 10.1038/s41586-020-2809-4 . hal03006522

\section{HAL Id: hal-03006522 \\ https://hal.science/hal-03006522}

Submitted on 19 Nov 2020

HAL is a multi-disciplinary open access archive for the deposit and dissemination of scientific research documents, whether they are published or not. The documents may come from teaching and research institutions in France or abroad, or from public or private research centers.
L'archive ouverte pluridisciplinaire HAL, est destinée au dépôt et à la diffusion de documents scientifiques de niveau recherche, publiés ou non, émanant des établissements d'enseignement et de recherche français ou étrangers, des laboratoires publics ou privés. 


\section{Seismic evidence for partial melt below tectonic plates}

2 Eric Debayle ${ }^{1}$, Thomas Bodin ${ }^{1}$, Stéphanie Durand ${ }^{1}$ and Yanick Ricard ${ }^{2}$

3 1Univ Lyon, Univ Lyon 1, ENSL, CNRS, LGL-TPE, F-69622, Villeurbanne, France

4 2Univ Lyon, ENSL, Univ Lyon 1, CNRS, LGL-TPE, F-69007, Lyon, France

6 The seismic low velocity zone (LVZ) of the upper mantle is generally 7 associated with a low-viscosity asthenosphere that plays a key role for the 8 dynamics of plate tectonics ${ }^{1}$. However, its origin remains enigmatic, some

9 authors attributing the reduction in seismic velocity to a small amount of partial melt ${ }^{2,3}$, others invoking solid-state mechanisms near the solidus ${ }^{4-6}$, or

11 the effect of volatile contents ${ }^{6}$. Observations of shear attenuation provide

12 additional constraints to unravel the origin of the $\mathrm{LVZ}^{7}$. Here, we report the 13 discovery of partial melt within the LVZ from the simultaneous 14 interpretation of global 3D shear attenuation and velocity models. We 15 observe that partial melting down to $150-200 \mathrm{~km}$ depth beneath mid-ocean 16 ridges, major hotspots and back-arc regions feeds the asthenosphere. A small 17 part of this melt $(<0.30 \%)$ remains trapped within the oceanic LVZ. The 18 amount of melt is related to plate velocities and increases significantly 19 between 3 and $5 \mathbf{c m ~ y r}^{-1}$, similar to previous observations of mantle crystal 20 alignement underneath tectonic plates $^{8}$. Our observations suggest that by 21 reducing viscosity ${ }^{9}$, melt facilitates plate motion and large-scale crystal 22 alignment in the asthenosphere. Melt is absent under most of the continents.

23 Our finding results from the simultaneous analysis of two upper mantle tomographic models of shear wave velocity (Vs) and attenuation (parameterised 
with Qs the quality factor, a measure of energy dissipation). Until now, most global tomographic studies of the upper mantle and their thermochemical interpretation have focused on shear velocity ${ }^{4,7}$. Recent experiments on olivine suggest that wave speed and attenuation are insensitive to water, which would imply that elevated water contents are not responsible for the LVZ10. However, Vs is sensitive to temperature, composition and melt content, and deciphering the causes of its variations represents a strongly non-unique inverse problem, severely limiting our understanding of the Earth's interior. Shear attenuation has a different sensitivity to these quantities, and therefore provides complementary constraints on the origin of seismic heterogeneities ${ }^{11}$. Shear attenuation is negligibly dependent on major element chemistry ${ }^{12}$, and exponentially dependent on temperature ${ }^{13}$. The relation between attenuation and melt is debated, with some authors arguing for a weak dependence based on experiments, models and seismological observations ${ }^{12}$, while others suggest a larger effect ${ }^{3}$. Measuring shear attenuation is nevertheless difficult. For this reason, only a few global Qs models have been published in the last 20 years ${ }^{14}$, and the only recent joint interpretation of $3 \mathrm{D}$ Qs and Vs tomographic models at global scale is based on models built from different datasets and modeling approaches ${ }^{15}$.

The novelty of our study is to simultaneously interpret two recent global Vs and Qs models that are consistent as obtained from the same Rayleigh wave dataset, at the same resolution and using the same modelling approach. These Vs (DR2020s) and Qs (QsASR17) models are displayed in Figure 1. Details of our tomographic procedure can be found in Methods. Before interpreting these two models in the light of laboratory experiments, a few words are needed to emphasize in what temperature and pressure range our interpretation is pertinent. The attenuation models derived by mineral physicists ${ }^{4,13}$ are valid for temperatures $T$ larger than $900^{\circ} \mathrm{C}$, which correspond to the base of the lithosphere and to the asthenosphere. 
They consider thermally activated processes varying exponentially with $1 / T$ that would imply quality factor in excess of 2,000 in the upper $100 \mathrm{~km}$ of the lithosphere and reaching several million near the surface (see Methods). However, finite Qs is observed in the crust and in the cold mantle lithosphere where attenuation is most likely related to non-thermal processes such as scattering or fluid-fracture interactions ${ }^{14}$. Furthermore, the attenuation observed in seismology accumulates along the seismic ray and the observation of Qs is only possible when the amplitude of a wave is measurably smaller than in a pure elastic model. Given the uncertainties on amplitude data, it appears impossible to resolve quality factors larger than $\sim 2,000$ with long period Rayleigh waves (at periods of $100 \mathrm{~s}$, assuming velocities of $4.5 \mathrm{~km} \mathrm{~s}^{-1}$ and ray lengths of $10,000 \mathrm{~km}$, the amplitude reduction with respect to a pure elastic model, would be less than $3.5 \%$ ). Our inversion leads indeed to a Qs model with strong lateral variations, by two orders of magnitudes, but with a maximum Qs of $\sim 1,750$. Our attenuation model is therefore mostly adapted to depths greater or equal to $\sim 100 \mathrm{~km}$, where Qs values between fifty and a few hundreds are expected ${ }^{15}$. Therefore, our interpretation applies to the oceanic asthenosphere and the mantle structure at depths greater or equal to $\sim 100 \mathrm{~km}$, where our tomographic models are acurate and where conditions similar to those used in laboratory experiments prevail.

Figure 2 displays Qs as a function of Vs for each pixel of the maps, at different depths in the upper mantle. The curves in dark and light blue represent the theoretical relations due to temperature variations for a meltless pyrolitic mantle ${ }^{16}$, given by two anelasticity models ${ }^{4,13}$ based on laboratory experiments, appropriate for asthenospheric conditions (see Methods for details). These models only explain a limited part of the velocities and attenuations of our dataset. We consider that the first theoretical curve ${ }^{4}$ is compatible with a given Vs-Qs observation if it falls within the typical uncertainties of the Vs and $\ln (\mathrm{Q} s)$ 
observations, $1 \%$ and $10 \%$ respectively (ivory colour). We show in Methods and supplementary Figures S1-10 that reconciling the low values of Vs with Qs cannot

81 be done by invoking radial anisotropy, elastically accomodated grain boundary sliding, or the effect of composition or water. However, this can be done by adding partial melt, thus reducing Vs, and shifting the theoretical curves to the left in Figure 2, since as discussed below, adding partial melt reduces Vs but has little effect on Qs. Warm colours in Figure 2 indicate the amount of melt $(<0.7 \%)$ needed to reconcile observations with the first theoretical model ${ }^{4}$ (dark blue curve), which requires the smallest amount of melt. On the right side of the ivory region, points in grey are those for which Vs is too high compared to the theoretical value. They are associated with the lithospheric depletion of cratonic roots. In this case, the grey intensity quantifies the departure in percent from the theoretical curve assuming a meltless pyrolitic mantle. Results using the second theoretical model ${ }^{13}$ are shown in Figures S11-12. They lead essentially to the same conclusions, but require larger melt fractions (up to 1\%), which are more difficult to reconcile with the very small melt fraction $(\sim 0.1 \%)$ suggested by geochemical studies ${ }^{4}$.

The effect of melt on Vs has been estimated to $7.9 \%$ reduction per percent of melt based on model calculations ${ }^{17}$. Recent experiments ${ }^{3}$ are in qualitative agreement but require a slightly larger Vs reduction (Figure S13). The effect of melt on attenuation is not well constrained and depends on the mechanisms of attenuation. We show in Methods that melt may have a large effect on Qs at short period (1 s), but not in the period range of surface waves (50-250s). We therefore

101 neglect the effect of melt on Qs and we model its effect on Vs based on recent 102 experiments $^{3}$. Figure 2 shows that the slowest shear velocities require less than $0.7 \%$ of melt. 
104 Figure 3 displays global maps of melt content at different depths, using the same

105 colour-coding as in Figure 2. The associated mantle temperatures, derived by our 106 approach are on average slightly above the solidus in oceanic regions, between 107100 and $200 \mathrm{~km}$ depth (Figure S14, panel g). The differences between the maps 108 of temperature (Figure S14 panels a-f) and those of melt content are attributed to 109 a variable amount of volatile ${ }^{9}$. A higher amount of volatiles above subduction 110 zones may lower the solidus and favor melting, while a dryer mantle in other 111 regions may impede melting. The heterogeneities in Figure $\mathbf{3}$ display a strong 112 correlation with surface tectonics. Regions where Vs is too high (in grey) are 113 located beneath continents down to $150 \mathrm{~km}$ depth. The discrepancy is likely due to 114 our assumption of a homogeneous and pyrolitic mantle. This assumption is 115 reasonable in the well-mixed convective mantle. However, beneath cratons, 116 compositional heterogeneities and depletion of incompatible elements are 117 contributing to the high seismic velocities. Our observations under cratons, at 150 $118 \mathrm{~km}$ depth, are on average $2.4 \%$ faster than a pyrolitic mantle which is compatible 119 with compositional effects ${ }^{18}$.

120 At $100 \mathrm{~km}$ depth, melt is required below mid-ocean ridges, some hotspots near the 121 Atlantic ridge and in the south Pacific Ocean, back-arc basins around the Pacific 122 Ocean including the eastern margin of Asia and some other active tectonic regions 123 (Afar, Tibet, West of North-America and Southwest Pacific, including the North 124 Fidji basin and the Northfolk ridge south of the Vanuatu arc). In these regions, the 125 amount of melt exceeds $0.3 \%$ and can reach $0.7 \%$. Melt is not required beneath 126 most of the remaining oceanic and continental Phanerozoic lithosphere where 127 temperature variations alone explain our observations.

128 The depth range 150-200 km corresponds to the oceanic LVZ, where a small 129 amount of melt $(<0.3 \%)$ is required over broad regions. The largest amount is 
beneath hotspots, ridges, and volatile-rich back-arc regions and can extend deeper

131 than the LVZ, suggesting that these deep regions feed the asthenosphere with

132 partial melt. For example, partial melt is observed down to $250 \mathrm{~km}$ beneath Hawaii and $300 \mathrm{~km}$ beneath the Afar and East-African rift, the hotspots located on the western part of North-America, the region of the Balleny Islands in Antarctica, the western Pacific and the Indian ocean near the Ninety-East ridge. A melting anomaly near $300 \mathrm{~km}$ on the eastern part of the Tibetan plateau is also observed.

137 The depth extent and amount of melt beneath oceanic regions are consistent with 138 local studies. The NoMELT experiment ${ }^{19}$ was performed beneath a location 139 relatively far away from Pacific hotspots (blue star in Figure 3) where we too 140 confirm the absence of melt in what could be a volatile-poor mantle. We observe melting beneath the East Pacific Rise (green star in Figure 3) down to $250 \mathrm{~km}$

142 depth, in agreement with the MELT experiment ${ }^{20}$. The depth extent of melting 143 beneath Hawaii down to $250 \mathrm{~km}$ is supported by measurements of water 144 abundance in the deep region that feeds the plume ${ }^{21}$. Our results agree with 145 observations of significant melting beneath the Philippine Sea plate and the 146 Western Pacific ${ }^{2}$. Finally, melting down to at least $300 \mathrm{~km}$ beneath the Balleny 147 Islands hotspot is also consistent with previous observations ${ }^{22}$.

148 The origin of partial melt within most of the oceanic LVZ is uncertain. Melting at 149 mid ocean-ridges can exceed $1 \%$ in the depth range $40-80 \mathrm{~km}^{20,23}$, but smaller 150 volume melting may occur down to depths of $150-250 \mathrm{~km}^{23}$. After melting at mid151 ocean ridges, a small amount of melt may remain unextractable from the mantle 152 peridotite $9,24,25$. Our observations suggest that decompression melting with at least 1530.3 to $0.7 \%$ of melt occurs also beneath some hotspots and back arc basins down to 154 about $200 \mathrm{~km}$. Most of the melt produced in these regions is extracted and 155 incorporated to the oceanic crust, but a small amount remains in the oceanic LVZ 
156 as it ages. The quantity of melt, if any, decreases close to continents below $0.1 \%$,

157 where a simple model without melt explains most of our observations. This may be

158 due to the difficulty of melting the depleted continental lithosphere. However under

159 tectonically active regions, beneath the Afar and East-African rifts, Tibet, Western

160 North-America and Transantarctic Mountains, the asthenosphere contains a small

161 amount of melt (Figure 3).

162 The quantity of melt needed to reconcile Vs and Qs under large swaths of the

163 oceanic LVZ is larger than usual estimates of unextractable melt, which range from 164 very small values ${ }^{9}$ to a maximum of $0.1 \%{ }^{24}$. Although melt is likely connected and 165 able to percolate even at very small porosity ${ }^{9}$, surface tension resists the phase 166 separation ${ }^{9,26}$. The ability of the melt to rise depends on various parameters, 167 surface tension, buoyancy, permeability, melt and matrix viscosities, which are all 168 known with large uncertainties ${ }^{25}$. The melt fractions greater than $0.1 \%$ that we 169 obtain are therefore plausible. This melt concentration is in overall agreement 170 with the range of estimates derived from electromagnetic studies ${ }^{27}$ of the LVZ, 171 which often propose even larger values (see Methods). A structure made of 172 magma-rich sills embedded in a meltless mantle might also be mapped by 173 tomography as an average medium with moderate melt content. This partially 174 molten layered model has been proposed for the northwest Pacific and Philippine 175 plates $^{2}$, but it could extend more generally to the entire oceanic LVZ. This layering 176 would explain both the radial anisotropy observed within the oceanic LVZ28 and 177 the sharp velocity and viscosity contrasts at the lithosphere-asthenosphere 178 boundary ${ }^{2}$.

179 Finally, the amount of melt exhibits a very peculiar relation with the plate 180 velocity $^{29}$ expressed in a no-net-rotation reference frame (Figure 4). The melt 181 fraction in the asthenosphere, abruptly increases by a factor close to 2 when the 
182 velocity is larger than $4 \mathrm{~cm} \mathrm{yr}^{-1}$. This variation is very similar to the observed

183 variation of azimuthal anisotropy with present-day plate motion ${ }^{8}$. Our results

184 suggest that plate-scale crystal alignment beneath fast-moving plates is associated

185 with a greater amount of melt. This requires either that melt facilitates

186 deformation ${ }^{9}$ or that deformation favours melt retention in the $\mathrm{LVZ}^{2}$, or both. In

187 any case, the small amount of melt observed beneath large swaths of the oceanic

188 LVZ is likely to significantly decrease viscosity (by one to two orders of 189 magnitude ${ }^{9}$, see Methods) and to play a significant role in the decoupling of

190 tectonic plates from the mantle.

References from main text:

192

1. Ricard, Y., Doglioni, C. \& Sabadini, R. Differential rotation between lithosphere and mantle -

a consequence of lateral mantle viscosity variations. J. Geophys. Res. 96, 8407-8415 (1991).

2. Kawakatsu, H. et al. Seismic Evidence for Sharp Lithosphere-Asthenosphere Boundaries of Oceanic Plates. Science 324, 499-502 (2009).

3. Chantel, J. et al. Experimental evidence supports mantle partial melting in the asthenosphere. Sci. Adv. 2, (2016).

4. Takei, Y. Effects of Partial Melting on Seismic Velocity and Attenuation: A New Insight from Experiments. in Annu. Rev. Earth Planet. Sci. (ed. Jeanloz, R and Freeman, K.) 45, 447-470 (2017).

5. Faul, U. H. \& Jackson, I. The seismological signature of temperature and grain size variations in the upper mantle. Earth Planet. Sci. Lett. 234, 119-134 (2005).

6. Karato, S. ichiro. On the origin of the asthenosphere. Earth Planet. Sci. Lett. 321-322, 95103 (2012).

7. Cobden, L., Trampert, J. \& Fichtner, A. Insights on Upper Mantle Melting, Rheology, and Anelastic Behavior From Seismic Shear Wave Tomography. Geochem., Geophy., Geosy., 19, 3892-3916 (2018).

8. Debayle, E. \& Ricard, Y. Seismic observations of large-scale deformation at the bottom of fast-moving plates. Earth Planet. Sci. Lett. 376, (2013).

9. Holtzman, B. K. Questions on the existence, persistence, and mechanical effects of a very small melt fraction in the asthenosphere. Geochemistry, Geophys. Geosystems 17, 470-484 (2016).

10. Cline, C. J., Faul, U. H., David, E. C., Berry, A. J. \& Jackson, I. Redox-influenced seismic properties of uppermantle olivine. Nature 555, 355-358 (2018).

11. Deschamps, F., Konishi, K., Fuji, N. \& Cobden, L. Radial thermo-chemical structure beneath Western and Northern Pacific from seismic waveform inversion. Earth Planet. Sci. Lett. 520, 153-163 (2019).

12. Shito, A., Karato, S., Matsukage, K. \& Nishihara, Y. Towards Mapping the Three-Dimensional Distribution of Water in the Upper Mantle From Velocity and Attenuation Tomography. Washingt. DC Am. Geophys. Union Geophys. Monogr. Ser. 168, (2006).

13. Jackson, I., Fitz Gerald, J. D., Faul, U. H. \& Tan, B. H. Grain-size-sensitive seismic wave attenuation in polycrystalline olivine. J. Geophys. Res., Sol. Earth., 107, 2360 (2002).

14. Romanowicz, B. A. \& Mitchell, B. J. 1.25 - Deep Earth Structure: Q of the Earth from Crust to Core. in Treatise on Geophysics (Second Edition) (ed. Schubert, G.) 789-827 (Elsevier, 2015). 
doi:https://doi.org/10.1016/B978-0-444-53802-4.00021-X

15. Dalton, C. A., Ekström, G. \& Dziewonski, A. M. Global seismological shear velocity and attenuation: A comparison with experimental observations. Earth Planet. Sci. Lett. 284, 6575 (2009).

16. Xu, W., Lithgow-Bertelloni, C., Stixrude, L. \& Ritsema, J. The effect of bulk composition and temperature on mantle seismic structure. Earth Planet. Sci. Lett. 275, 70-79 (2008).

17. Hammond, W. C. \& Humphreys, E. D. Upper mantle seismic wave velocity: Effects of realistic partial melt geometries. J. Geophys. Res. Solid Earth 105, 10975-10986 (2000).

18. Bruneton, M. et al. Layered lithospheric mantle in the central Baltic Shield from surface waves and xenolith analysis. Earth Planet. Sci. Lett. 226, 41-52 (2004).

19. Lin, P. Y. P. et al. High-resolution seismic constraints on flow dynamics in the oceanic asthenosphere. Nature 535, 538-541 (2016).

20. Yang, Y., Forsyth, D. W. \& Weeraratne, D. S. Seismic attenuation near the East Pacific Rise and the origin of the low-velocity zone. Earth Planet. Sci. Lett. 258, 260-268 (2007).

21. Wallace, P. J. Water and partial melting in mantle plumes: Inferences from the dissolved H2O concentrations of Hawaiian basaltic magmas. Geophys. Res. Lett. 25, 3639-3642 (1998).

22. Sieminski, A., Debayle, E. \& Lévêque, J.-J. Seismic evidence for deep low-velocity anomalies in the transition zone beneath West Antarctica. Earth Planet. Sci. Lett. 216, (2003).

23. Key, K., Constable, S., Liu, L. \& Pommier, A. Electrical image of passive mantle upwelling beneath the northern East Pacific Rise. Nature 495, 500+ (2013).

24. Faul, U. H. Melt retention and segregation beneath mid-ocean ridges. Nature 410, 920-923 (2001).

25. Selway, K. \& O'Donnell, J. P. A small, unextractable melt fraction as the cause for the low velocity zone. Earth Planet. Sci. Lett. 517, 117-124 (2019).

26. Hier-Majumder, S., Ricard, Y. \& Bercovici, D. Role of grain boundaries in magma migration and storage. Earth Planet. Sci. Lett. 248, 735-749 (2006).

27. $\mathrm{Ni}, \mathrm{H} ., \mathrm{K}$ Keppler, H. \& Behrens, H. Electrical conductivity of hydrous basaltic melts: Implications for partial melting in the upper mantle. Contrib. to Mineral. Petrol. 162, 637650 (2011).

28. Chang, S.-J. J., Ferreira, A. M. G. G., Ritsema, J., van Heijst, H. J. \& Woodhouse, J. H. Joint inversion for global isotropic and radially anisotropic mantle structure including crustal thickness perturbations. J. Geophys. Res. Solid Earth 120, 4278-4300 (2015).

29. DeMets, C., Gordon, R. G., Argus, D. F. \& Stein, S. Effect of recent revisions to the geomagnetic reversal time-scale on estimates of current plate motions. Geophys. Res. Lett. 21, 2191-2194 (1994).

Acknowledgements. We thank the Iris and Geoscope data centers for providing seismological data. We also thank two anonymous reviewers for their comments, J.P. Perrillat and M. Behn for discussions on mineralogy and attenuation models, and F. Dubuffet for preparing data for sharing as IRIS Data Products. The European Union Horizon 2020 research and innovation program funds T. B. under grant agreement 716542. The LABEX Lyon Institute of Origins (LIO, ANR-10-LABX0066) of the University of Lyon funded a beowulf cluster hosted and maintained at ENSL, and used in this study. The world map figures were created with open software GMT 4.5.13. 
271 Author contributions. E.D. and T.B. collaborated in developing the concept of this

272 paper. E.D. wrote the codes for the interpretation of the seismic models and wrote

273 the drafts of the manuscript. E.D. wrote the tomography code for Vs, Y.R. adapted

274 this code for Qs. T.B. contributed to the design of the figures and to the writing of

275 the manuscript. Y.R. developed preliminary codes for interpreting the seismic

276 models, contributed to all mineralogical aspects and to the writing of the

277 manuscript. S.D realized the tests of the effect of composition and contributed to

278 the writing of the revised manuscript.

279

280

281

282

283

284

285

286

287

288

289

290

291

292

293

294

295

296

297

298

299

300

301

302

303

304

305

306

307

308

309

310

Fig. 1: Shear velocity and attenuation in the upper mantle. Panels a-c-e-g: perturbations in shear wave velocities from DR2020s shown in percent with respect to a mean value $V_{\text {ref }}$ given in $\mathrm{km} \mathrm{s}^{-1}$ above the colour scale. Panels b-d-f-h: maps of our Qs tomographic model QsADR17 at different depths in the upper mantle. Qs is plotted with a logarithmic scale. Its geometric average is given above the colour scale. Hotspot locations are shown with black triangles.

Fig. 2: Scatter plot depicting the observed shear attenuation as a function of shear velocity compared with theoretical predictions. The velocities (from DR2020s) and attenuation values (from QsADR17) are plotted at $100 \mathrm{~km}$ (panel a), $150 \mathrm{~km}$ (panel b) and $200 \mathrm{~km}$ depth (panel c). Each dot corresponds to a geographical location. The dark blue and light blue curves are the theoretical predictions assuming a pyrolitic composition ${ }^{34}$ in the absence of melt using the anelasticity models of Takei ${ }^{4}$ and Jackson et al.13, respectively. The upper colour scale indicates the amount of melt in percent required to explain our observations using Takei4's model. Adding melt enables to lower the predicted velocity without changing Qs. The lower grey scale indicates the misfit in percent between theory and observations, in regions where Vs is too high and cannot be reconciled with model predictions assuming a pyrolitic mantle.

Fig. 3: Melt content at different depths in the upper mantle. This melt content is derived from the joint interpretation of QsADR17 and DR2020s. The colour coding is identical to Figure 2. Melt content in percent is indicated with warm colour from ivory ( $0 \%$ melt) to brown $(0.4$ to $0.7 \%$ melt). The grey scale indicates the misfit in percent between theory and observations, in regions where Vs is too high compared with predictions. Hotspots locations are indicated with black triangles. The blue and green stars indicate the location of the NoMELT and MELT experiments, respectively. 
312 Fig. 4: Percentage of melt at different depths as a function of absolute plate velocity.

313 (The velocities ${ }^{29}$ are expressed in a no-net-rotation reference frame. The percentage of

314 melt is averaged for all geographical points with similar plate velocities, using a sliding

315 window of $\pm 2 \mathrm{~cm} \mathrm{yr}^{-1}$. The amount of melt increases significantly in the asthenosphere

$316(100-200 \mathrm{~km})$ for plate velocities between 3 and $5 \mathrm{~cm} \mathrm{yr}^{-1}$. This result links with previous

317 observations that only plates moving faster than $4 \mathrm{~cm} \mathrm{yr}^{-1}$ can organize the flow at large

318 scale in the underlying asthenosphere ${ }^{8}$, suggesting that melt reduces viscosity ${ }^{9}$ and

319 facilitates large-scale crystal alignment. 


\section{Methods}

322 Qs and Vs tomographic models. Figure 1 presents maps of DR2020s, a new

323 global Vs model and QsADR17 a recent global Qs model ${ }^{30}$. Both models are built

324 from the same massive Rayleigh wave measurements ${ }^{31}$, and are obtained from a

325 similar tomographic procedure. The first step is an automated waveform inversion

326 approach which was applied to approximately 375,000 Rayleigh seismograms ${ }^{31}$.

327 From a single surface wave seismogram, the waveform inversion extracts

328 simultaneously a path-average depth-dependent shear velocity profile, Vs, and

329 quality factor, Qs. By jointly interpreting the amplitude and phase of each

330 waveform, we ensure that the interplay between Vs and Qs is accounted for, and

331 that the shear quality factor and velocity profiles are constrained within the same

332 period range. The waveform analysis is performed in the period range 50-250 $\mathrm{s}$

333 and accounts for the fundamental and up to the 5th higher mode of Rayleigh

334 waves, thus ensuring a good depth resolution for Vs and Qs from $50 \mathrm{~km}$ depth

335 down to the transition zone. It is a non-linear iterative process, which also

336 produces frequency-dependent phase velocity and attenuation curves compatible

337 with the recorded waveform. The effect of physical dispersion due to attenuation is

338 accounted for in the modelling.

339 The second step is a regionalization of the 1D path-average models. DR2020s is

340 obtained from the regionalization at each depth of the path-average Vs models

341 using a continuous regionalization approach ${ }^{31}$. This tomographic inversion yields

342 3D absolute velocities. QADR17, a global model of Rayleigh-wave attenuation was

343 obtained after adapting the same regionalization approach to our dataset of

344 Rayleigh wave attenuation curves, parameterized as $\ln (Q)^{32}$. The regionalisation of

345 the path-average attenuation curves accounts for frequency-dependent effects like

346 focussing-defocussing, which can have important effects on the amplitude of 
347 Rayleigh waves. The logarithmic parameterization brings the distribution of the

348 quality factor dataset close to a Gaussian, allows the large variations of Q

349 documented by local seismic studies and guarantees to avoid negative attenuation

350 values in the inverted model. The horizontal smoothing in DR2020s and QADR17

351 is determined by a Gaussian a priori covariance function controlled by an angular

352 correlation length. Adenis et al. ${ }^{32}$ chose a conservative value of $10^{\circ}$ (meaning that

353 the Q model is resolved accurately up to spherical harmonic 12). Debayle and

354 Ricard $^{31}$ used a shorter correlation length of $3.6^{\circ}$ for their Vs model DR2012. We

355 re-inverted their dataset using a correlation length of $10^{\circ}$ in order to obtain a Sv-

356 wave tomographic model at the same horizontal resolution and vertical smoothing

357 than QsADR17. To minimize biases due to un-modelled radial anisotropy, we

358 computed the isotropic Voigt average of our Sv model and the Sh model obtained

359 by adding the radial anisotropy of PREM to our Sv model. The resulting isotropic

360 model DR2020s is plotted in Figure 1. Using other 1D or 3D models of radial

361 anisotropy does not affect our conclusions, as discussed below. QsADR17 was

362 obtained from the inversion at depth of QADR1730, using the same vertical

363 smoothing as for DR2020s. DR2020s and QsADR17 are therefore consistent since

364 they are derived from the simultaneous inversion of the same waveforms and

365 inverted using the same regionalization approach with the same Gaussian filtering.

366 Prediction of Qs and Vs using a temperature-dependent model ${ }^{4}$. The dark blue

367 curve in Figure 2 is obtained by predicting Vs and Qs at each depth for a range of

368 temperatures, using a temperature-dependent anelasticity model ${ }^{4}$ and assuming a

369 pyrolitic composition ${ }^{16}$. This model parameterizes the relaxation spectrum with a

370 small number of variables determined from experimental data. It accounts for a

371 monotonic background spectrum plus a broad temperature-dependent absorption

372 peak in the seismic frequency band, whose amplitude and width increase below

373 the solidus. This produces a significant enhancement of polycrystal anelasticity 
374 before melting. This pre-melting effect induces large Vs reductions under the 375 solidus. We choose the solidus according to Hirschman ${ }^{33}$. We use the model

376 parameters given in Tables 1 and 2 of Takei ${ }^{4}$, except for the unrelaxed shear 377 modulus $\mu_{U}$. We estimate $\mu_{U}$ for a pyrolitic mantle using the mineralogic phase diagram computed by the Perple X software ${ }^{34}$. In Figures S15-S16 we show the results obtained with the shear modulus of Takei $^{4}$, which reduces the amount of melt in oceanic regions but fails to explain our $\ln (\mathrm{Q})$-Vs observations beneath old oceanic basins at $100 \mathrm{~km}$ depth. It also significantly increases the misfit beneath continents.

Prediction of Qs and Vs from the experimental results of Jackson et al. ${ }^{13}$. The light blue curve in Figure $\mathbf{2}$ is obtained by a two-step process. First, we use experimental results on melt-free polycrystalline olivine to predict a theoretical quality factor $Q_{t}$. Computations are performed in the temperature range 800-1800

$387 \mathrm{~K}$ and the pressure range $1.49-12.99 \mathrm{GPa}$, corresponding to the depth range 50$390 \mathrm{~km}$. We use the following relation ${ }^{13}$ :

390 In this formulation, $Q_{t}^{-1}$ at period $T_{0}$ depends on the temperature $T$, the pressure $P$ 391 and to a lesser extent the grain size $d . R$ is the gas constant, $E$ is the activation 392 energy and $V$ is the activation volume. Table S1 summarizes the values of the 393 different parameters of Eq. A.1. In the range of values compatible with 394 experiments ${ }^{13}$, we choose $T_{0}=100 \mathrm{~s}$, the average period of our long period Rayleigh 395 waves and $d=0.01 \mathrm{~m}$. The theoretical curves corresponding to Eq. A1 are shown in 396 Figure S9, with the effect of changing grain size.

397 Second, we use Perple $\mathrm{X}^{34}$ to estimate an isotropic Vs for a pyrolitic model ${ }^{16}$. We 398 compute Vs for the same temperatures and pressures as $Q_{t}$. Perple_X produces 
399

400

401

402

403

404

405

406

407

408

409

410

411

412

413

414

415

416

417

418

419

420

421

422

423

unrelaxed S-wave velocities at infinite frequency, above the absorption band of seismic attenuation, while our long period (>50 s) seismic surface waves are likely to see relaxed velocities. We therefore correct for the effect of anelasticity on $\mathrm{Vs}^{35}$ :

$$
V_{s}^{t}=V_{s \infty}\left(1-\frac{Q_{t}^{-1}\left(T_{0}, T, P, d\right)}{2 \tan (\pi \alpha / 2)}\right) \quad \text { Eq. A.2 }
$$

where $V_{s \infty}$ is the unrelaxed velocity and $V_{s}^{t}$ is the velocity corrected from the effect of attenuation. According to Eq. A2, the stronger the attenuation, the stronger the velocity reduction is. The light blue curve in Figure $\mathbf{2}$ is finally obtained by plotting at a given depth the obtained $\ln \left(Q_{t}\right)$ as a function of $V_{s}^{t}$ for each temperature.

Comparison between our observations and the theoretical relations. At each geographical location and depth, we extract the observed value of Qs in QsADR17 and Vs in DR2020s and we compare our observations with the chosen theoretical relation. We consider that a theoretical curve is compatible with a given Vs-Qs observation if it falls within $\pm 1 \%$ and $\pm 10 \%$ of the Vs and $\ln (\mathrm{Q} s)$ observations, respectively (Figure 2). These errors are on the conservative side of recent estimates $^{36,37}$. If the theoretical relation cannot explain our observations, two situations can arise: 1 ) the observed Vs is lower than the theoretical $V_{S}^{t}$. In this case melt can be added to reduce $V_{s}^{t}$. This is done assuming melt has no effect on Qs; 2) the observed Vs is higher than $V_{s}^{t}$. This is mostly the case under continents and can be explained by the depletion of the pyrolitic mantle increasing the theoretical $\mathrm{V}_{\mathrm{S}}^{\mathrm{t} 18}$.

Effect of grain size. Grain sizes in the shallow upper mantle are likely 1-20 mm as observed in upper mantle xenoliths, harzburgite and dunite bodies ${ }^{13}$. The effect of grain size on Eq. A1 is shown in Figure S9. The blue areas around the theoretical curves cover the influence of grain size from $1 \mathrm{~mm}$ (bottom dot curve) to an upper bound of $100 \mathrm{~mm}$ (upper dashed curve). For a given value of Qs, increasing the 
grain size increases the temperature and therefore decreases the velocity. As melt is required for explaining slow velocities, increasing grain size will decrease the amount of melt required to explain our observations. Using the equation A1 proposed by Jackson, we show in Figure $\mathbf{S 1 2}$ melt distributions obtained for $d=0.01 \mathrm{~m}$ and in Figure $\mathbf{S 1 7}$ those for the extreme value $d=0.1 \mathrm{~m}$, which minimizes the amount of melt required in the LVZ. Maps in Figure S17 are similar to those of Figure S12 with a smaller amount of melt. However, in both cases, amounts of melt are larger than for our preferred model using the equations of Takei ${ }^{4}$ (Figure 3).

Amounts of melt. Although the amount of melt present in the LVZ depends on the choice of the anelasticity model and on the effect of melt on Vs, we show in Figures S12, S16, S17, S18 that different choices of parameters yields similar maps and that melt fractions away from source regions always stay below 1\%, in agreement with the partially molten asthenosphere model ${ }^{2}$. We note however that our preferred anelasticity model $^{4}$ generally explains our Vs and $\ln (\mathrm{Qs})$ observations without the need of partial melt above and below the asthenosphere (Figure 3).

440 This is therefore a conservative choice, able to reconcile our Vs and $\ln (\mathrm{Q})$ 441 observations in most of the upper mantle, while minimizing the amount of melt required in the $\mathrm{LVZ}$.

443 Effect of radial anisotropy. We used the anisotropic parameter $\xi=(\mathrm{Vsh} / \mathrm{Vsv})^{2}$ of 444 PREM to convert our Sv observations into an isotropic model, DR2020s. We 445 checked that 3D models of $\xi$ obtained from anisotropic models like SEMUM238 or 446 S362 $\mathrm{ANI}^{39}$ would not affect our main conclusions. As an example, Figure S1 is 447 similar to Figure 3 but based on our Sv observations corrected with the 448 anisotropic $\xi$ parameters of SEMUM2 (Figure S2). Only minor changes are 449 observed (for example in the Pacific or Indian oceans at 150 and $200 \mathrm{~km}$ ), but 
450

451

452

453

454

455

456

457

458

459

460

461

462

463

464

465

466

467

468

469

470

none that would change the interpretations of this paper. The lateral variations of $\xi$ in SEMUM2 (Figure S2) are too small to affect our results. To confirm this point, we computed the anisotropy $\xi$ that would be needed to account for the discrepancy between observed Qs and Vs, without invoking mantle depletion or partial melt (Figure S3). Comparison of this figure with Figure S2 shows that neither the patterns nor the amplitude would fit (a 3 to 4 times larger anisotropy than in SEMUM2 would be needed to explain our observations). The anisotropy therefore does not affect our conclusions.

\section{Elastically accommodated grain boundary sliding (EAGBS) hypothesis.}

Anelastic relaxation caused by EAGBS can produce a sharp velocity reduction and may explain the LAB and the mid-lithosphere discontinuity observed beneath continents ${ }^{40}$. We tested the EAGBS hypothesis as an alternative explanation to partial melting for reconciling Vs and Qs in the LVZ. EAGBS is characterized by a sharp attenuation peak at a characteristic frequency $\omega_{E A G B S}$, followed by a diffused absorption band at lower frequencies. We first compute the characteristic frequency for the transition between unrelaxed and relaxed shear moduli. It is given by Karato et al., ${ }^{40}$ :

$\omega_{E A G B S}=A \cdot d^{-1} \cdot \exp \left(-\frac{E^{*}+P V^{*}}{R \cdot T}\right) \cdot\left[1+\left(\frac{C_{w}}{C_{w 0}}\right)^{r}\right]$

Eq. A3

where $\mathrm{C}_{\mathrm{w}}$ is the water content in wt $\%, A=2.3 \times 10^{-14} \mathrm{~m} \mathrm{~s}^{-1}, C_{w 0}=10^{-4} \mathrm{wt} \%, r=1$, $E^{*}=350 \mathrm{~kJ} \mathrm{~mol}^{-1}, V^{*}=10^{-6} \mathrm{~m}^{3}, d=5 \times 10^{-3} \mathrm{~m}$. Following Cobden et al. ${ }^{7}$ we assume a dry mantle with $\mathrm{C}_{\mathrm{w}}=10^{-6} \mathrm{wt} \%$.

471 Surface waves analysed at frequencies lower than $\omega_{E A G B S}$ should see relaxed 472 velocities within the absorption band (see Fig. SI- 2 of Karato et al. ${ }^{40}$ ), providing 473 depth and temperature are within the activation ranges of EAGBS. EAGBS is 474 activated between 60 and $160 \mathrm{~km}$ depth in the temperature range 900-1,350 K. We 
475

476

477

478

479

480

481

482

483

484

485

486

487

488

489

490

491

492

493

494

495

496

497

498

499

consider that EAGBS may affect the interpretations of our long period ( $>40 \mathrm{~s}$ ) Qs and Vs maps when $\omega_{E A G B S}>0.025 \mathrm{~Hz}$ and, from figure 4 of Karato et al. ${ }^{40}$, in the following temperature ranges for the depths of our tomographic inversion:

- $70 \mathrm{~km}: 930-1,140 \mathrm{~K}$

- $90 \mathrm{~km}: 980-1,180 \mathrm{~K}$

- $100 \mathrm{~km}: 1,010-1,220 \mathrm{~K}$

- $125 \mathrm{~km}: 1,060-1,270 \mathrm{~K}$

- $150 \mathrm{~km}: 1,130-1,330 \mathrm{~K}$

Regions where EAGBS can apply are displayed in green in Figure S4. These regions correspond mostly to continental areas. Assuming that EAGBS correction applies, Karato et al. ${ }^{40}$ list three alternative formulations for the velocity reduction. The Ghahremani ${ }^{41}$ equation, which produces the smallest velocity reduction is :

$$
V_{s}^{e a g b s}=V_{s}^{t} \cdot \sqrt{\frac{0.86-0.83 v}{1-v} \cdot \frac{1+v}{1.14+0.83 v}} \quad \text { Eq. A.4 }
$$

where $v$ is the Poisson's ratio ( $\sim 0.3$ for upper mantle minerals). Regions where this can reconcile our Vs and Qs observations are displayed in red in Figure S4. The two other formulations give too large velocity reduction. Figure $\mathbf{S 4}$ shows that EAGBS fails at reconciling our long period observations, excepted in a few localized regions (in red). This does not preclude EAGBS to play a significant role in explaining the sharp velocity reduction associated with the LAB, which cannot be resolved by long period surface waves. However, the strong velocity reduction observed within the LVZ requires another mechanism.

Effect of composition. Compositional heterogeneities exist in the upper mantle, likely in the domain limited by pyrolite, harzburgite and pyroxenite ${ }^{42}$. Here, we check the effect of changing the composition from pyrolite to these end-members using Perple $\mathrm{X}^{34}$ to compute the velocities. Pyroxenites have variable bulk 
500 compositions $^{43}$ and we consider both a silica-deficient composition (see, Stixrude 501 and Lithgow-Bertelloni ${ }^{44}$, Table 1) and a silica-excess composition similar to that 502 of a subducted basalt (see, Xu et al.,16, Table 1). A silica-excess pyroxenite would 503 only be faster that pyrolite after eclogitization, below $150 \mathrm{~km}$ depth (Figure S5, orange curve). At $100 \mathrm{~km}$ depth, a mantle made entirely of silica-excess pyroxenite would be too slow to explain the observed velocities (Figure S6). At larger depth, after eclogitization, it would lead to large melt fractions (Figure S6). The silicadeficient pyroxenite and the harzburgite are characterized at asthenospheric conditions by much faster or comparable velocities than pyrolite (Figure S5) and hence cannot explain the low velocities that we attribute to the presence of melt.

510 Harzburgite would give melt fractions and distribution similar to pyrolite (Figure

511 S7), while the silicate-deficient pyroxenite would lead to higher melt fractions (up 512 to $1.7 \%$ ) and a ubiquitous melt presence below $150 \mathrm{~km}$ depth (Figure S8).

513 Pyroxenite, whether enriched or depleted in silica, should only be present in a 514 small proportion $(\sim 5 \%)^{42}$ that hardly affects the seismic velocities of the peridotitic mantle. At any rate, large-scale chemical heterogeneities (> $1000 \mathrm{~km}$ )

516 are not likely to exist in the LVZ, where viscosity is small (below $10^{20} \mathrm{~Pa}$ s) and the 517 convective mantle should be well stirred and mixed. Therefore, our observations cannot be explained by reasonable variations of compositions in the LVZ.

Possible effect of water. Although, it has been recently shown that in olivine, wave-speed and attenuation are insensitive to water ${ }^{10}$, some previous studies had suggested an effect of water quantified following the equation ${ }^{45}$ :

$$
Q_{t}^{-1}\left(T_{0}, T, P, C_{O H}, d\right)=A\left(T_{0} d^{-1}\left(\frac{C_{O H}}{C_{O H(r e f)}}\right)^{r} \exp (-(E+P V) / R T)\right)^{\alpha} \quad \text { Eq. A.5 }
$$
where $C_{O H}$ is the water concentration, $r$ is a dimensionless constant and all other parameters are as in Eq. A1. The average $\mathrm{H}_{2} \mathrm{O}$ content of Earth's upper mantle is estimated in the range $50-200 \mathrm{ppm}^{46}$. We test a value close to the upper bound 
$526\left(C_{O H}=1000 \mathrm{H} / 10^{6} \mathrm{Si}\right.$, corresponding to $125 \pm 75 \mathrm{ppm}$ by weight of water $)$ with $r=1$, a 527 standard value for moderate water content and $C_{O H(r e f)}=50 \mathrm{H} / 10^{6} \mathrm{SI}^{7}$. The 528 corresponding theoretical curves are shown in blue on Figure S9. At fixed 529 temperature, water increases attenuation. However to keep Q constant, an 530 increase of water content must be balanced by a decrease of temperature and 531 therefore by a higher expected velocity $V_{s}^{t}$. Reconciling this higher $V_{s}^{t}$ with our 532 observations requires larger amounts of melt (Figure S10). Therefore, if there were 533 an effect of water on Vs and Qs, it would increase the required amount of melt.

534 Effect of melt on attenuation. A small amount of melt might have a large effect on attenuation ${ }^{47}$ in the case of grain boundary sliding, where a broad dissipation peak

536 is observed in the seismic frequency band. Body wave studies have reported low 537 Qs values at short period (1s) with Qs $\leq 25$ beneath the Juan de Fuca and Gorda 538 ridges $^{48}$ and $25 \leq \mathrm{Q} \leq \leq 80$ in the back-arc mantle of Central America, the Marianas 539 and the Lau Basin ${ }^{49}$. A recent experimental study suggests that $0.2 \%$ of melt 540 produces $Q s=48^{3}$. However such a large effect of melt on Qs is difficult to reconcile with long period (>30 s) surface waves observations of $Q s=80$ beneath the fast

542 spreading southern East pacific Rise ${ }^{20}$ where up to $1-2 \%$ of melt is expected ${ }^{50}$. If 543 the attenuation mechanism is melt squirt, then the dissipation peak may lie outside 544 the seismic frequency band and cause little attenuation. Model calculations ${ }^{51}$, long545 period surface waves ${ }^{20}$ and experiments ${ }^{12}$ favour such interpretation. This is also 546 supported by our long period (100 s) global surface wave tomographic models, 547 which suggest that strong Vs and Qs reductions are not necessarily correlated ${ }^{30,32}$. 548 For these reasons, we assume that in the period range of surface waves (50-250s), 549 melt does not significantly affects attenuation and we neglect its effect on Qs.

550 Temperature in the upper mantle. Our Qs and Vs seismic models are interpreted 551 using mineral physics results ${ }^{4,13}$. These experimental results are valid at temperatures 
552 larger than $900^{\circ} \mathrm{C}$ or $1000^{\circ} \mathrm{C}$, which are reached at the base of the lithosphere and in the asthenosphere. The predictions of our model can be checked with respect to the well-

554 known thermal behaviour of the cooling oceanic lithosphere ${ }^{52,53}$ although this is 555 certainly pushing the model outside its applicability range. Figure S19 (panel a), 556 displays the temperature variations beneath the Pacific as a function of sea-floor age

557 predicted from our seismic models using experimental results ${ }^{4}$. It demonstrates that 558 even at depths shallower than $100 \mathrm{~km}$, we retrieve the well-known age-dependence of temperature in oceanic regions (we also pick up the cold signal of the West Pacific subductions at old ages). However, our temperature variations between the ridge and an old lithosphere $\left(\sim 100^{\circ}\right)$ are lower than the predictions of the plate-cooling model $\left(250^{\circ}\right.$ at $75 \mathrm{~km}$ depth, panel b). Panel c displays the quality factors that would be deduced

563 from the plate-cooling model using the experimental results ${ }^{4}$ used in this paper. In the oceanic lithosphere, Qs values much greater than $2000(\ln (\mathrm{Qs})>7.6)$ would be predicted, that cannot be retrieved by long period seismology. The limitations of experimental data at low temperatures together with the inability of surface wave seismology to quantify precisely negligible attenuations, explain why we do not interpret results at depths shallower than $100 \mathrm{~km}$. Below the oceanic plates, Figure S14, panel $\mathbf{g}$ shows that our predicted temperatures beneath oceans are perfectly compatible with geodynamic and petrologic expectations. In agreement with our findings, under oceans, the average $1 \mathrm{D}$ temperature profile is above the solidus ${ }^{4}$ and the adiabat ${ }^{54}$ in the depth range 100-200 km, where we predict partial melting. This overshoot of the temperature, above the adiabat, is indeed found in all numerical simulations

574 of mantle convection ${ }^{55}$. Under continents, the temperature appears to be below the 575 solidus $^{4}$ and the adiabat ${ }^{54}$. It reaches the adiabat around $250 \mathrm{~km}$ depth (Figure 576 S14, panel g).

577 Compatibility of our results with electrical conductivity. Our results are consistent with the interpretation of a number of recent studies of electrical 
579

580

581

582

583

584

585

586

587

588

589

590

591

592

593

594

595

596

597

598

599

600

601

602

603

conductivity. In the depth range 100-150 km, the joint interpretation of electrical and seismic data ${ }^{56}$ requires $0.3-2.5 \%$ of melt beneath the mid-Atlantic ridge, $1 \%$ or less melt beneath Hawaï and less than $5 \%$ of melt beneath the East-pacific rise, in good agreement with Figure 3. We also confirm the absence of melt in the region of the NoMELT experiment ${ }^{19}$, in agreement with conductivity data in this region ${ }^{25}$. Previous experimental results suggest that between 0.3 and $2 \%$ of hydrous basaltic melt can account for the observed electrical conductivity in the LVZ ${ }^{27}$. A more recent study ${ }^{57}$ has refined these results by simultaneously measuring wave velocity and electrical conductivity on a simplified partial melt analogue. They conclude that the low velocity zone away from spreading ridges can be explained by $0.3-0.8 \%$ volatile-bearing melt, the upper bound of our observations.

Implications for viscosity. The variation of viscosity as a function of melt content occurs in two steps ${ }^{9}$. The onset of melting brings already a significant effect on viscosity when a connected network of melt tubules is formed. The viscosity $\eta$ is expected to decrease by one or two orders of magnitude before the melt fraction $\varphi$ reaches $0.1 \%$. For larger melt content, $\eta$ decreases further ${ }^{9}$ with $d \ln (\eta) / d \varphi=-26$ but this effect is minor for the low melt content that we observe. Under oceanic plates where $\varphi$ is around $0.3 \%, \eta$ should be one or two orders of magnitude lower than under continents.

Data availability: The dataset generated during this study (3D Vs, Qs models and melt fraction models) is available as IRIS data products at https://doi.org/10.17611/dp/emc.2020.dbrdnature.1.

Code availability: Numerical modelling codes related with this paper can be downloaded from https://doi.org/10.17611/dp/emc.2020.dbrdnature.1. Requests about the numerical modelling codes associated with this paper should be sent to 
606 Competing interest: The authors declare no competing interests.

\section{References from Methods:}

30. Adenis, A., Debayle, E. \& Ricard, Y. Attenuation tomography of the upper mantle. Geophys. Res. Lett. 44, (2017).

31. Debayle, E. \& Ricard, Y. A global shear velocity model of the upper mantle from fundamental and higher Rayleigh mode measurements. J. Geophys. Res., Sol. Earth., 117, (2012).

32. Adenis, A., Debayle, E. \& Ricard, Y. Seismic evidence for broad attenuation anomalies in the asthenosphere beneath the Pacific Ocean. Geophys. J. Int. 209, 1677-1698 (2017).

33. Hirschmann M. M. Mantle solidus: Experimental constraints and the effects of peridotite composition. Geochemistry Geophys. Geosystems 1, 1042 (2000).

34. Connolly, J. A. D. Computation of phase equilibria by linear programming: A tool for geodynamic modeling and its application to subduction zone decarbonation. Earth Planet. Sci. Lett. 236, 524-541 (2005).

35. Karato, S. Importance of anelasticity in the interpretation of seismic tomography. Geophys. Res. Lett. 20, 1623-1626 (1993).

36. Zaroli, C. Global seismic tomography using Backus-Gilbert inversion. Geophys. J. Int. 207, 876-888 (2016).

37. Resovsky, J., Trampert, J. \& der Hilst, R. D. Error bars for the global seismic Q profile. Earth Planet. Sci. Lett. 230, 413-423 (2005).

38. French, S., Lekic, V. \& Romanowicz, B. Waveform Tomography Reveals Channeled Flow at the Base of the Oceanic Asthenosphere. Science 342, 227-230 (2013).

39. Kustowski, B., Ekstrom, G. \& Dziewonski, A. M. Anisotropic shear-wave velocity structure of the Earth's mantle: A global model. J. Geophys. Res. 113, (2008).

40. Karato, S. I., Olugboji, T. \& Park, J. Mechanisms and geologic significance of the midlithosphere discontinuity in the continents. Nat. Geosci. 8, 509-514 (2015).

41. Ghahremani, F. Effect of grain boundary sliding on anelasticity of polycrystals. Int. J. Solids Struct. 16, 825-845 (1980).

42. Hirschmann, M. M. \& Stolper, E. M. A possible role for garnet pyroxenite in the origin of the “'garnet signature"' in MORB. Contrib. Miner. Pet. 124, 185-208 (1996).

43. Lambart, S., Laporte, D. \& Schiano, P. Markers of the pyroxenite contribution in the majorelement compositions of oceanic basalts: Review of the experimental constraints. Lithos 160, 14-36 (2013).

44. Stixrude, L. \& Lithgow-Bertelloni, C. Mineralogy and elasticity of the oceanic upper mantle: Origin of the low-velocity zone. J. Geophys. Res. Solid Earth 110, B03204 (2005).

45. Behn, M. D., Hirth, G. \& Elsenbeck, J. R. Implications of grain size evolution on the seismic structure of the oceanic upper mantle. Earth Planet. Sci. Lett. 282, 178-189 (2009).

46. Hirschmann, M. M. Water, melting, and the deep Earth H2O cycle. Annu. Rev. Earth Planet. Sci. 34, 629-653 (2006).

47. Faul, U. H., Fitz Gerald, J. D. \& Jackson, I. Shear wave attenuation and dispersion in meltbearing olivine polycrystals: 2. Microstructural interpretation and seismological implications. J. Geophys. Res. Solid Earth 109, 1-20 (2004).

48. Eilon, Z. C. \& Abers, G. A. High seismic attenuation at a mid-ocean ridge reveals the distribution of deep melt. Sci. Adv. 3, (2017).

49. Abers, G. A. et al. Reconciling mantle attenuation-temperature relationships from seismology, petrology, and laboratory measurements. Geochem., Geophy., Geosy., 15, 35213542 (2014). 
653
50. Dunn, R. A. \& Forsyth, D. W. Imaging the transition between the region of mantle melt generation and the crustal magma chamber beneath the southern East Pacific Rise with short-period Love waves. J. Geophys. Res. Solid Earth 108, 2352 (2003).

51. Hammond, W. C. \& Humphreys, E. D. Upper mantle seismic wave attenuation: Effects of realistic partial melt distribution. J. Geophys. Res. Solid Earth 105, 10987-10999 (2000).

52. Turcotte, D. L. \& Schubert, G. Geodynamics: Applications of Continuum Physics to Geological Problems. (John Wiley \& Sons, New York, 1982).

53. Stein, C. A. \& Stein, S. A model for the global variation in oceanic depth and heat flow with lithospheric age. Nature, 359, 123-129 (1992).

54. Katsura, T. et al. Adiabatic temperature profile in the mantle. Phys. Earth Planet. Inter. 183, 212-218 (2010).

55. Curbelo, J. et al. Numerical solutions of compressible convection with an infinite Prandtl number: comparison of the anelastic and anelastic liquid models with the exact equations. J. Fluid Mech. 873, 646-687 (2019).

56. Pommier, A. \& Garnero, E. J. Petrology-based modeling of mantle melt electrical conductivity and joint interpretation of electromagnetic and seismic results. J. Geophys. Res., Sol. Earth., 119, 4001-4016 (2014).

57. Freitas, D., Manthilake, G., Chantel, J., Bouhifd, M. A. \& Andrault, D. Simultaneous measurements of electrical conductivity and seismicwave velocity of partially molten geological materials: effect of evolving melt texture. Phys. Chem. Miner. 46, 535-551 (2019). 


\section{$100 \mathrm{~km}$}

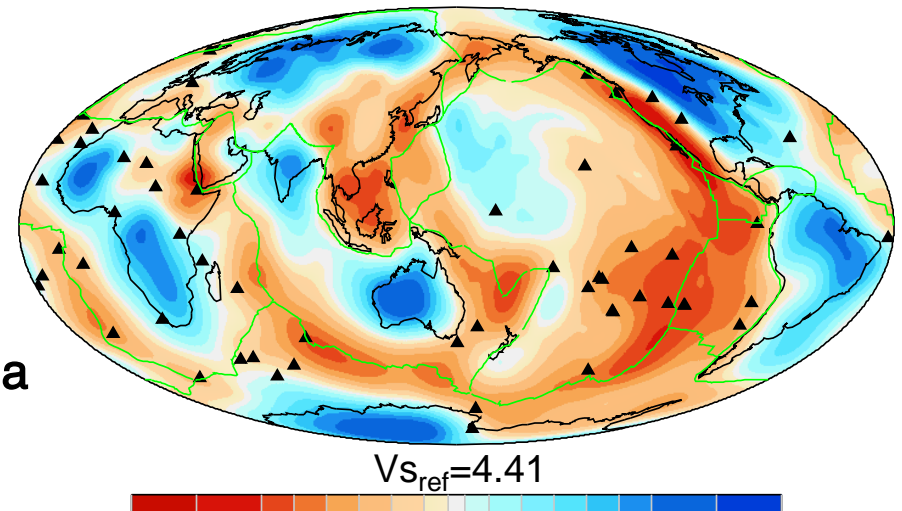

$\begin{array}{llllll}-10 & -5 & -2 & 2 & 5 & 10\end{array}$

$150 \mathrm{~km}$

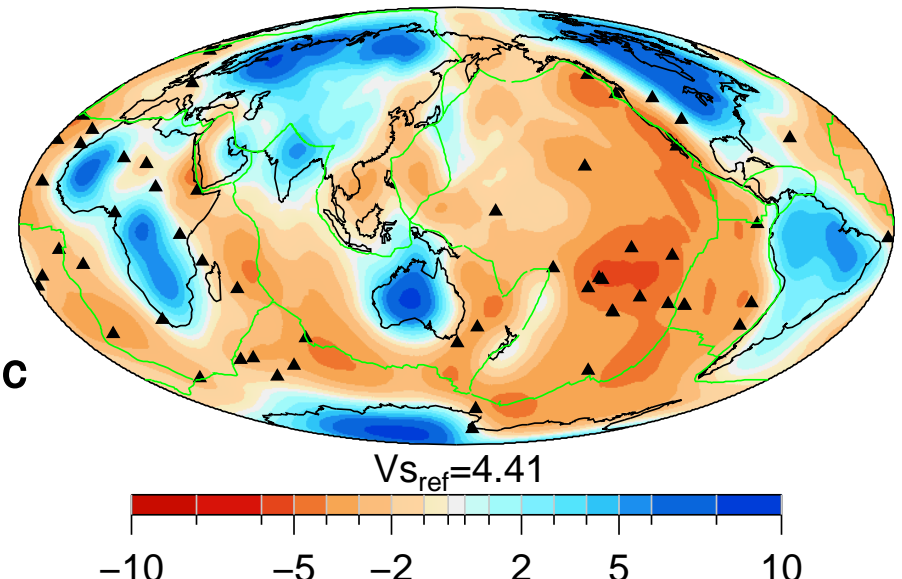

$200 \mathrm{~km}$

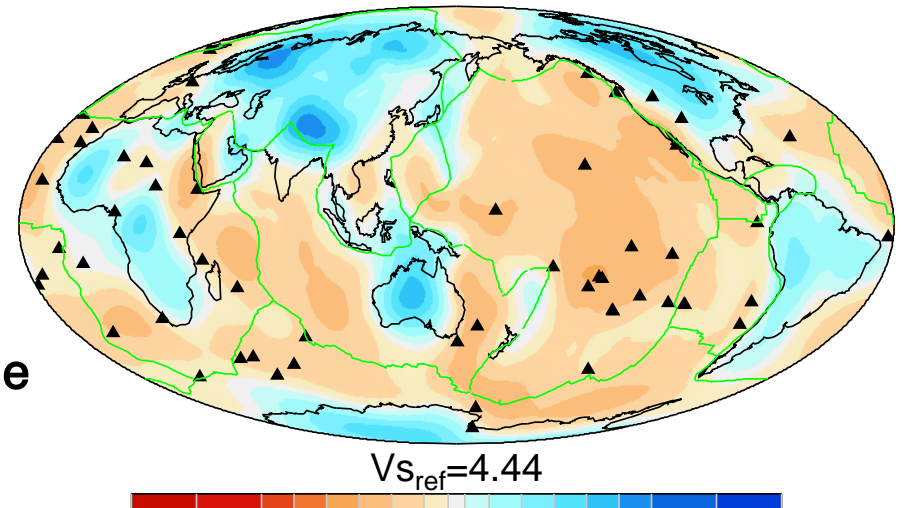

$\begin{array}{lllll}-10 & -5 & -2 & 2 & 5\end{array}$

10

$300 \mathrm{~km}$

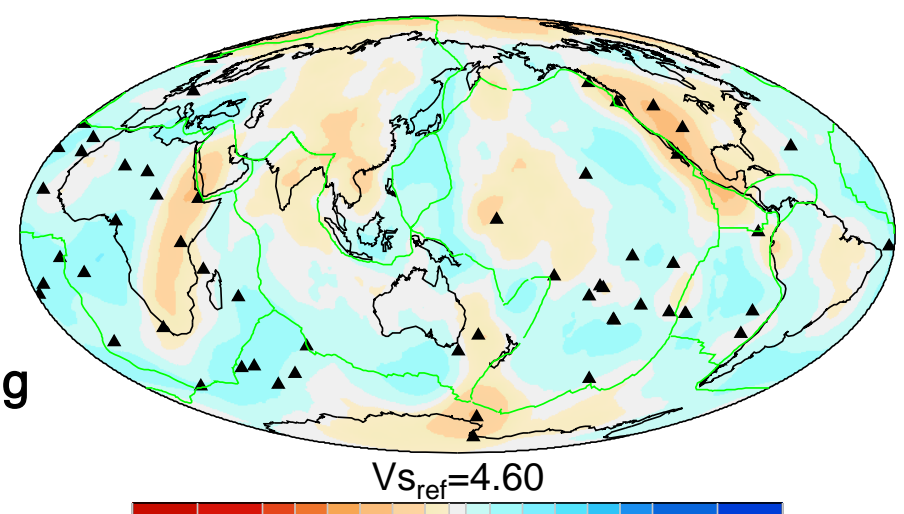

$-10$

25

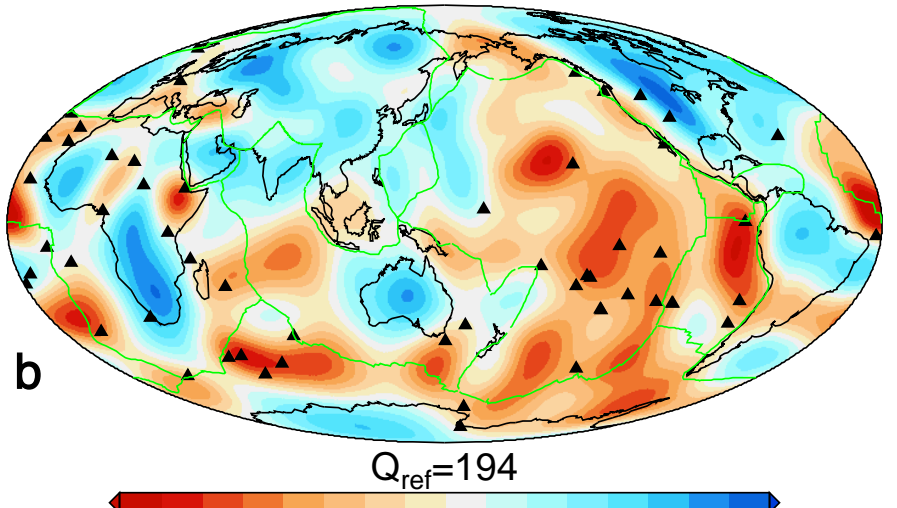

$\begin{array}{lcccc}50 & 100 & 200 & 500 & 1000\end{array}$
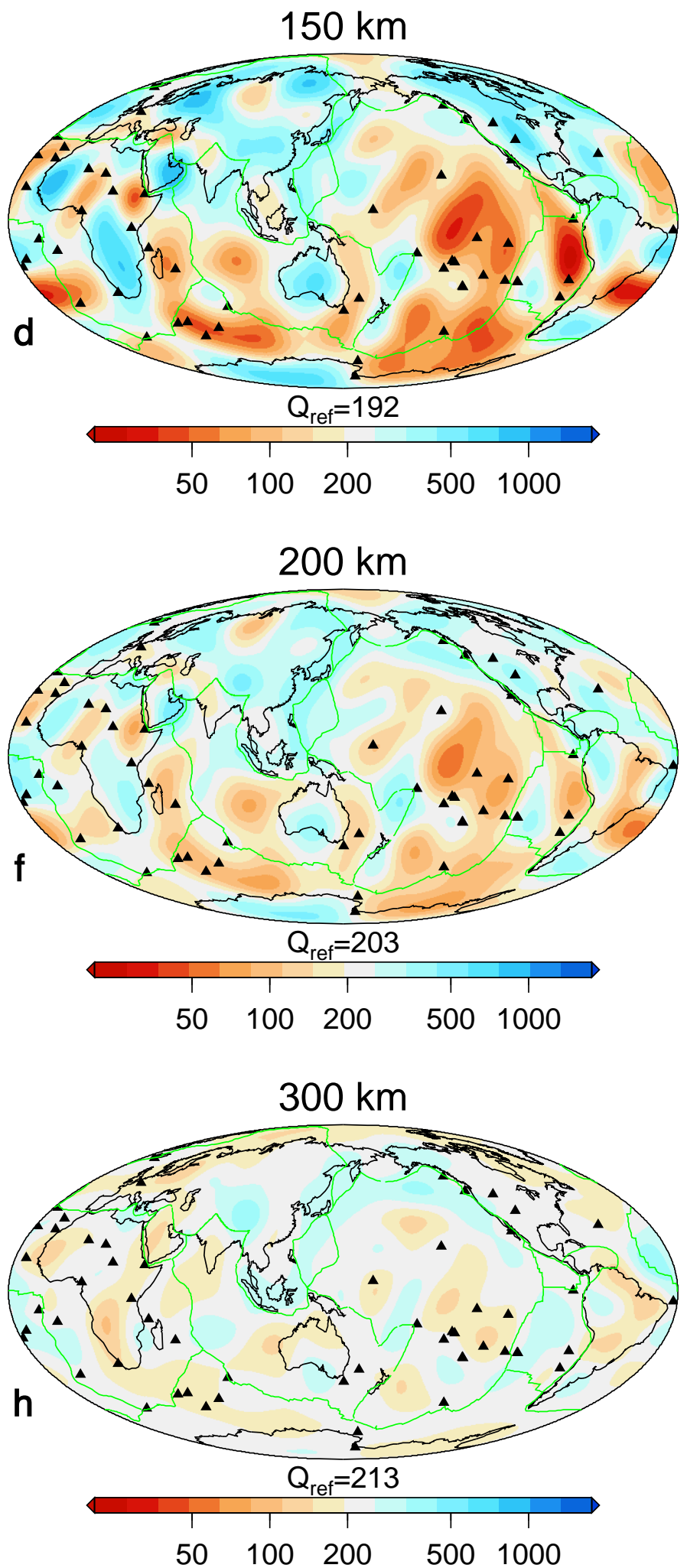

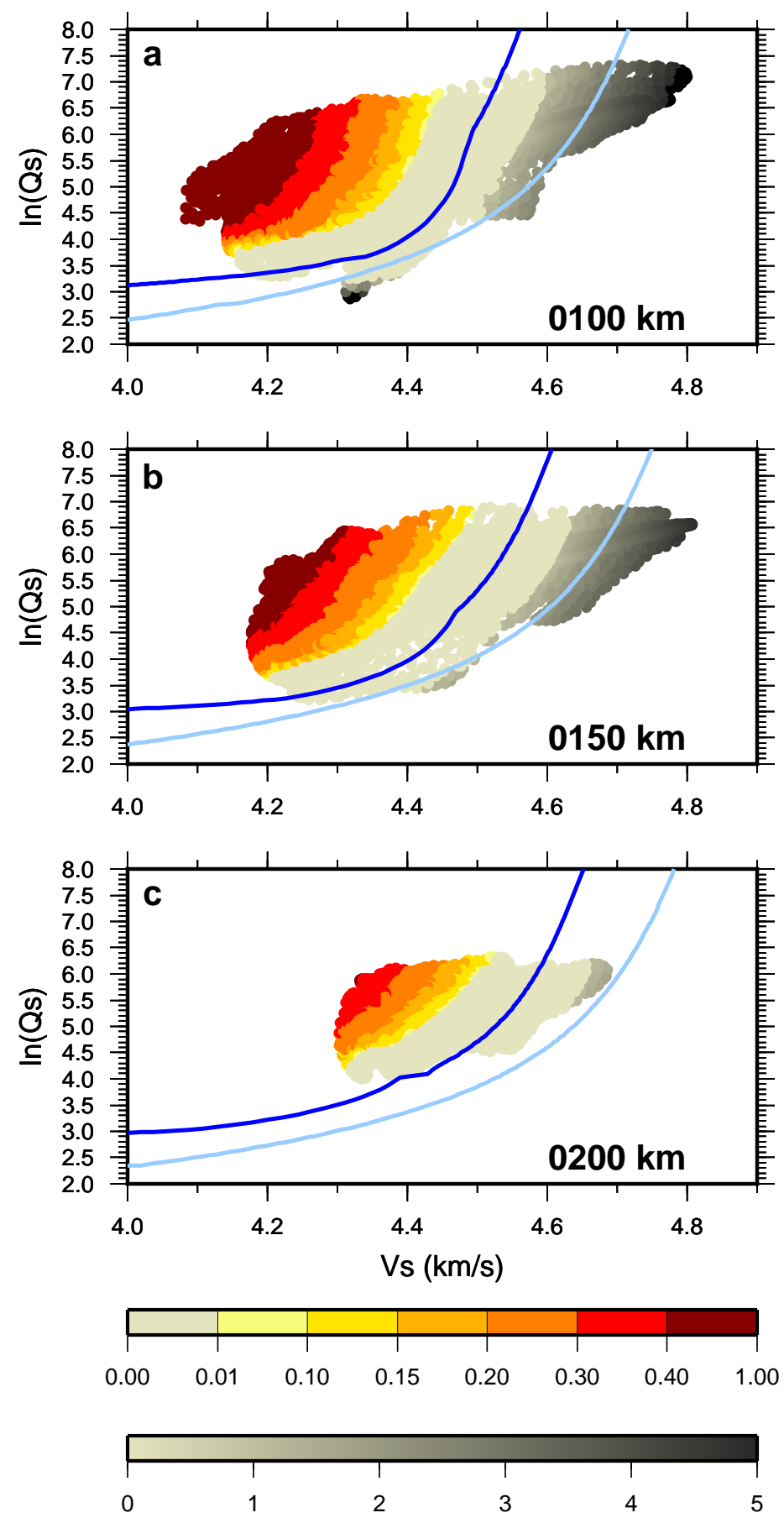

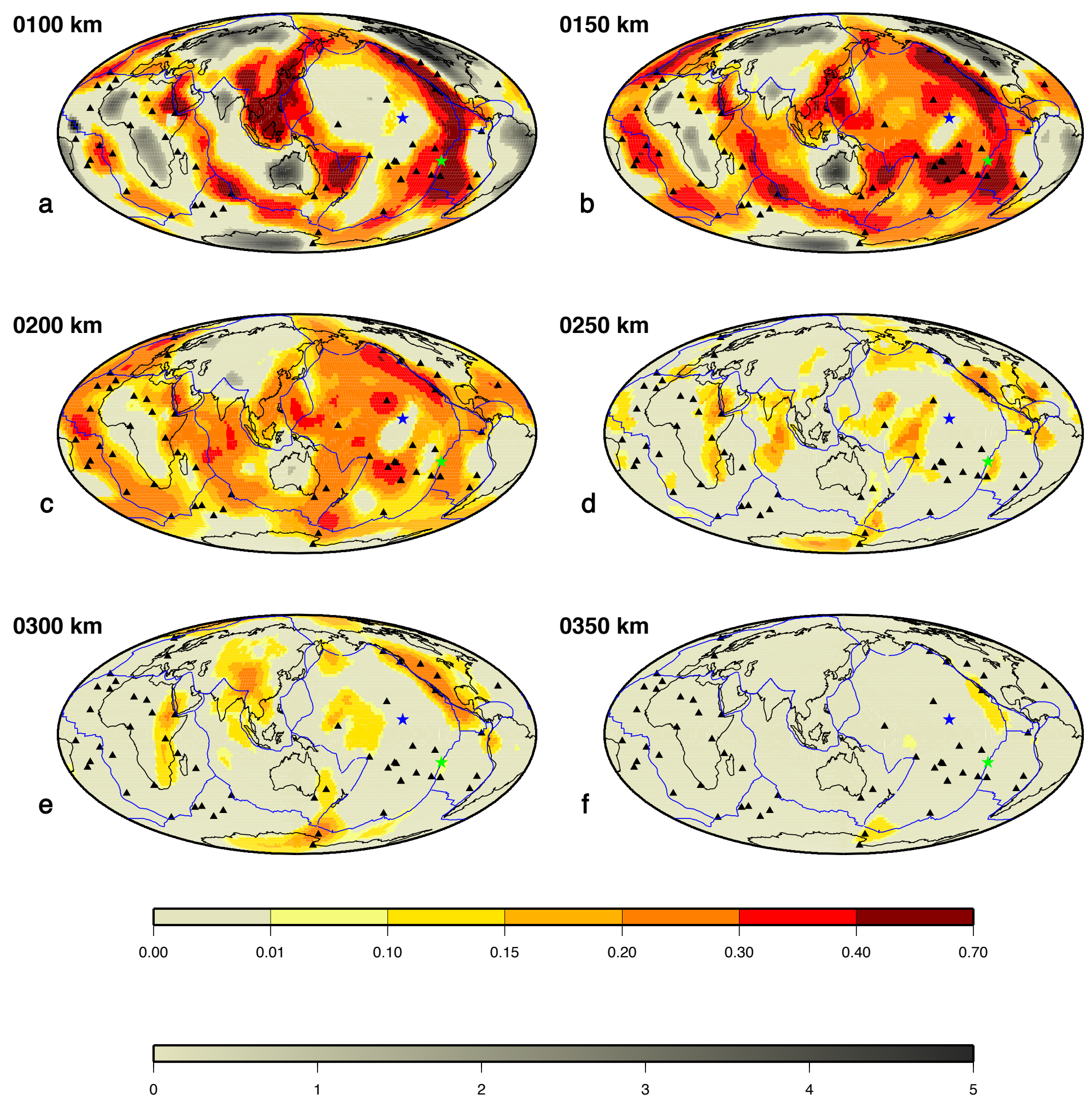


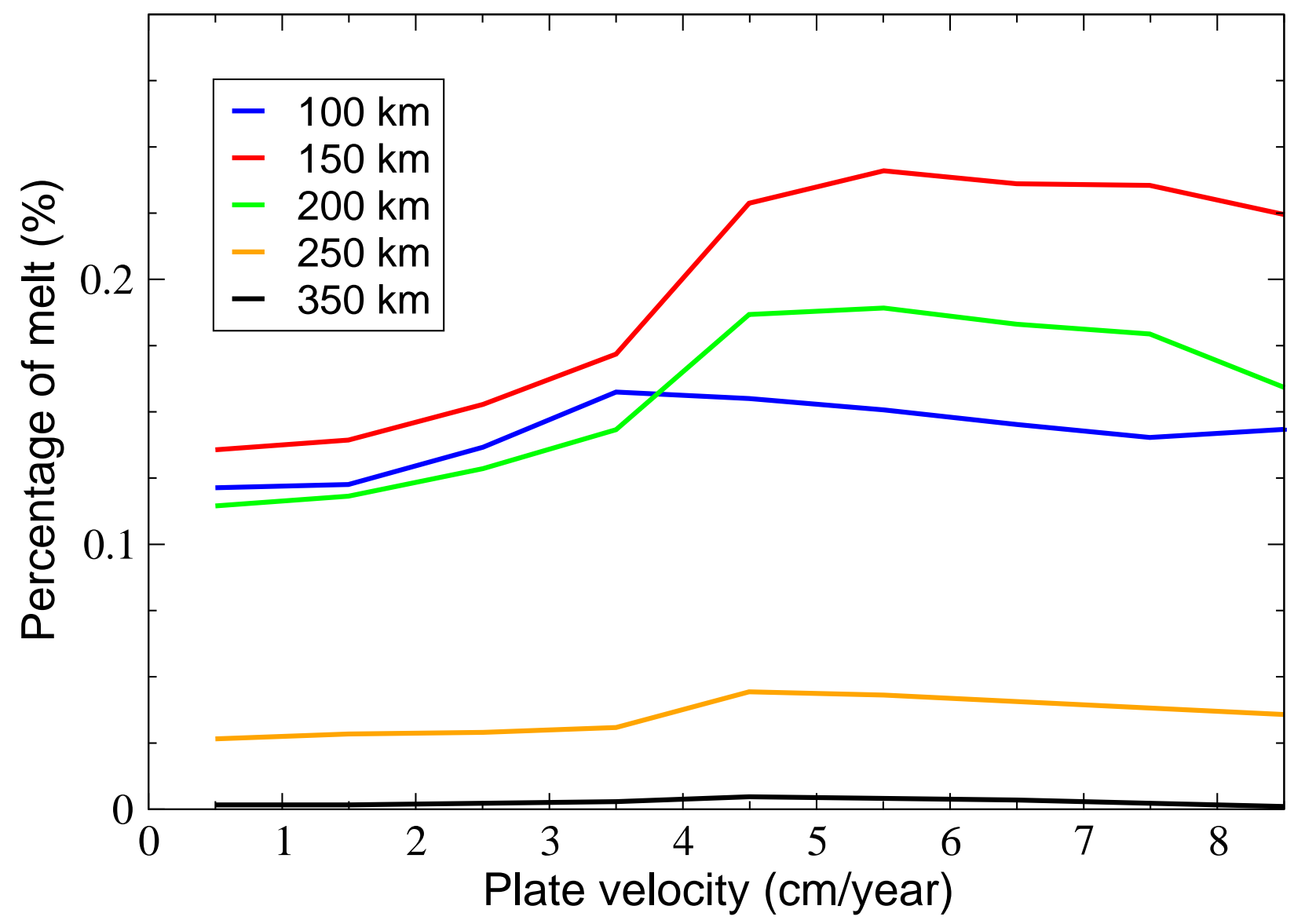




\begin{tabular}{l|lll}
\hline Symbol & Description & Value & Units \\
\hline$\alpha$ & exponent & 0.26 & \\
$\mathrm{~A}$ & prefactor & $7.5 \times 10^{-2}$ & $\mathrm{~s}^{-\alpha} \mu \mathrm{m}^{\alpha}$ \\
$\mathrm{d}$ & grain size & $1-100$ & $\mathrm{~mm}$ \\
$\mathrm{~T}_{0}$ & period & 100 & $\mathrm{~s}$ \\
$\mathrm{E}$ & activation energy & 424 & $\mathrm{~kJ} / \mathrm{mol}$ \\
$\mathrm{V}$ & activation volume & $6 \times 10^{-6}$ & $\mathrm{~m} / \mathrm{mol}$ \\
\hline
\end{tabular}

Table S1: Reference parameters for Eq.A.1 after Jackson et al. ${ }^{1}$ 

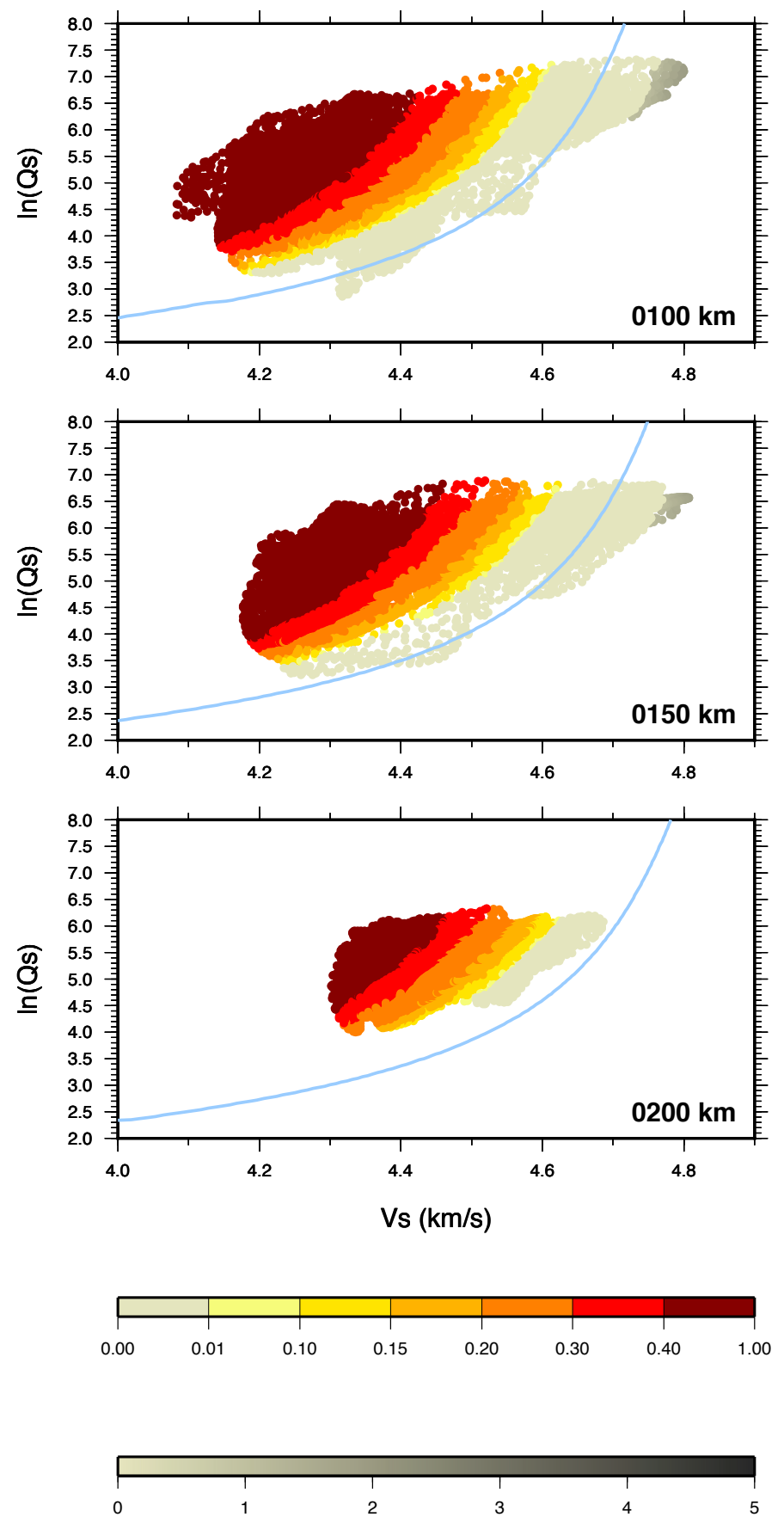

Fig. S1: same as Figure 2 but the color scales indicate the departure from the model of Jackson et al. ${ }^{1}$ (light blue curve), for a grain size of $10 \mathrm{~mm}$. The upper color scale indicates the amount of melt in percent required to explain our observations (ivory color from 0 to $0.01 \%$ of melt underlines data for which the model can reconcile our Qs and Vs observations). The lower grey scale indicates the misfit in percent between theory and observations, in regions where Vs is too high and cannot be reconciled with model predictions. 

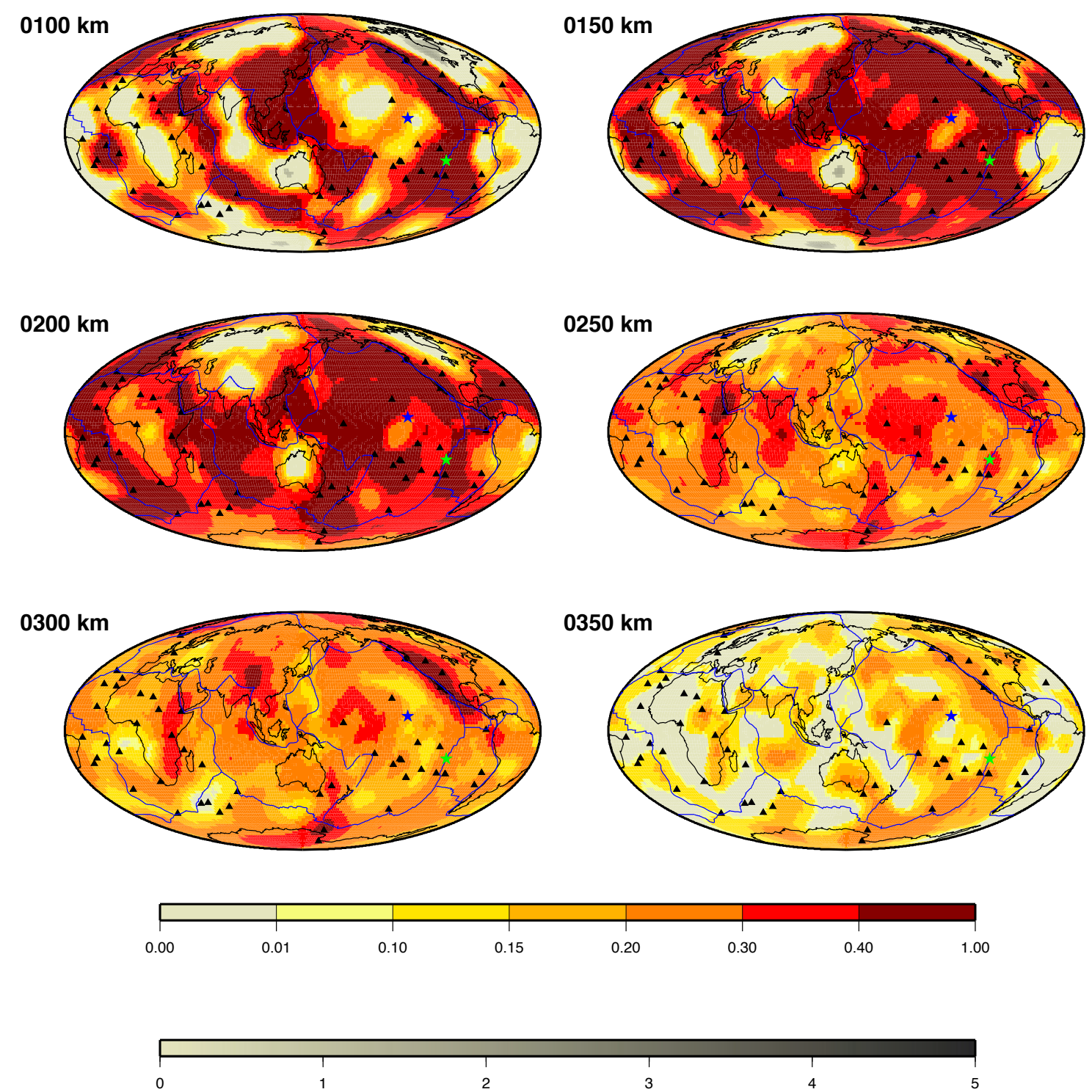

Fig. S2: same as Figure 3 but color scales indicate the departure from the model of Jackson et al. ${ }^{1}$, for a grain size of $10 \mathrm{~mm}$. Melt content in percent is indicated with warm colors (upper color scale) from ivory ( $0 \%$ melt) to brown $(0.4$ to $0.7 \%$ melt). The lower grey scale indicates the misfit in percent between the theory and observations, in regions where Vs is too high compared with predictions. 


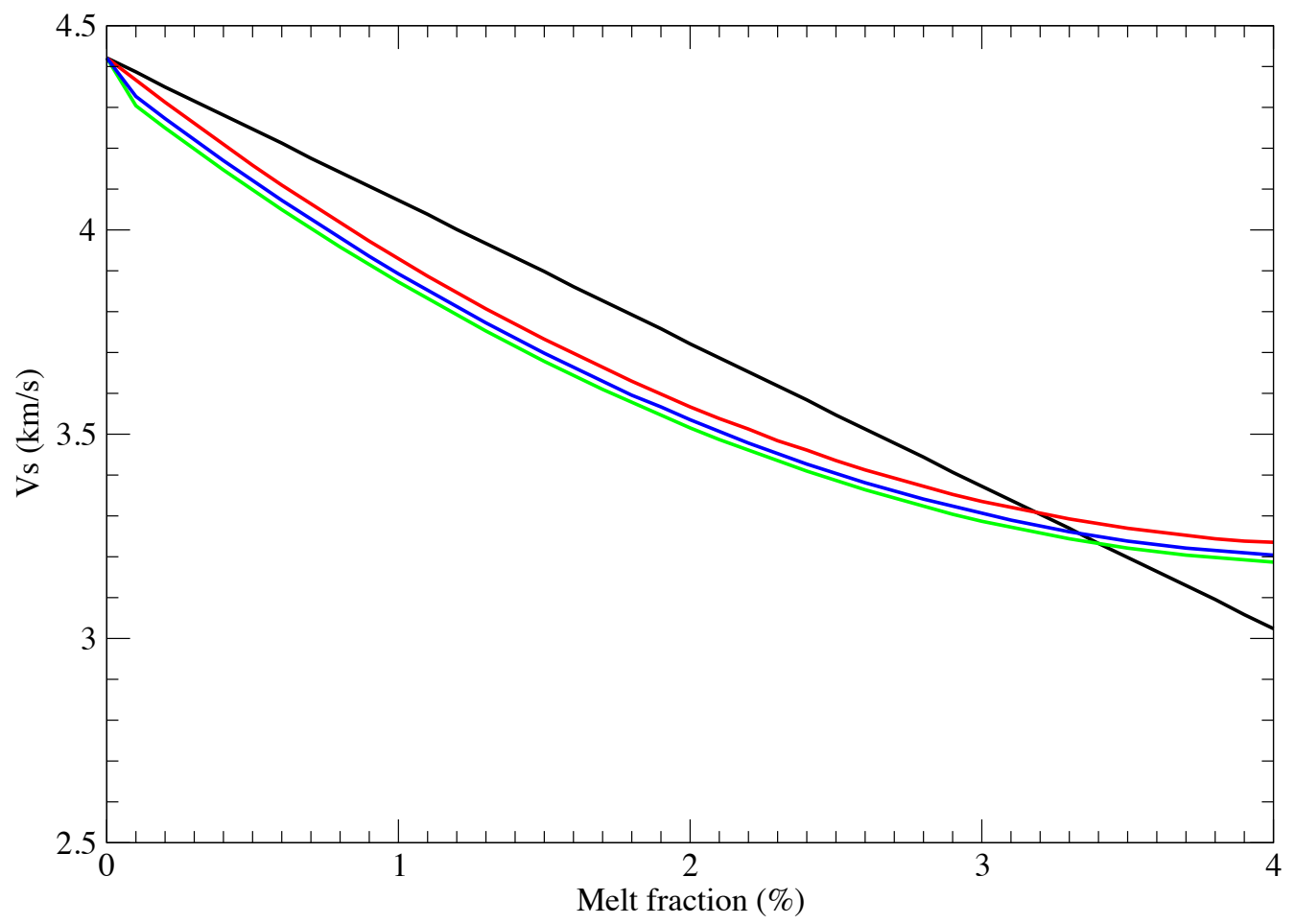

Fig. S3: Dependence of shear velocity on melt fraction $\varphi$. The linear Vs reduction of 7.9\% per percent of melt ${ }^{2}$ is shown in black from a reference velocity $V_{\text {ref. }}$ The polynomial expression $\left(V_{s}=0.065 \varphi^{2}-0.5565 \varphi+V_{\text {ref }}\right)$ derived from experimental results ${ }^{3}$ is shown in red. The anelastic effect expected for seismic waves at high temperature ${ }^{4}$ is shown assuming $\mathrm{Q} s=80$, the value of $\mathrm{PREM}^{5}$ in the asthenosphere, for two values of $\alpha$ (blue curve for $\alpha=0.38$ and green curve for $\alpha=0.26)$. For small melt fractions $(<1 \%)$, a stronger Vs reduction is obtained using the polynomial expression and the choice of $\alpha$ has a small effect. 

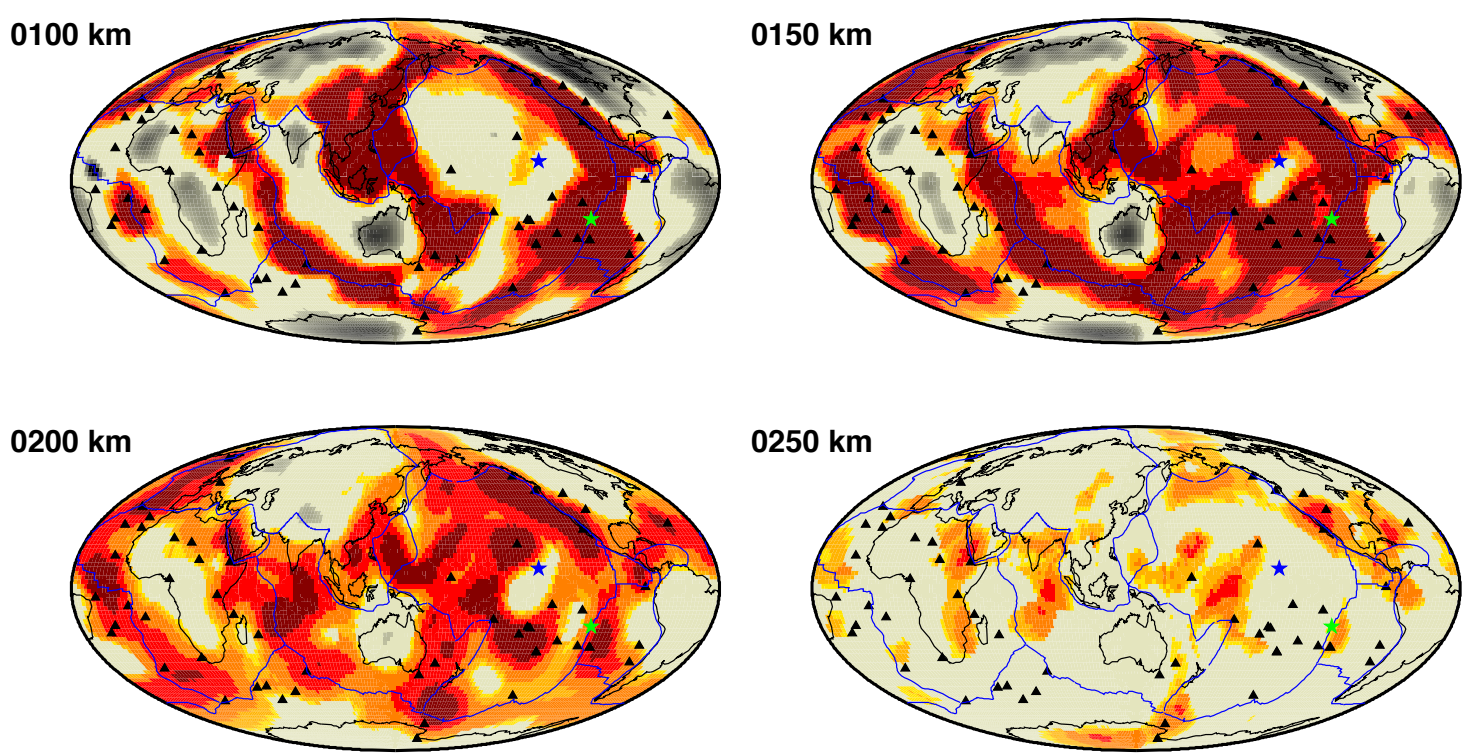

0250 km
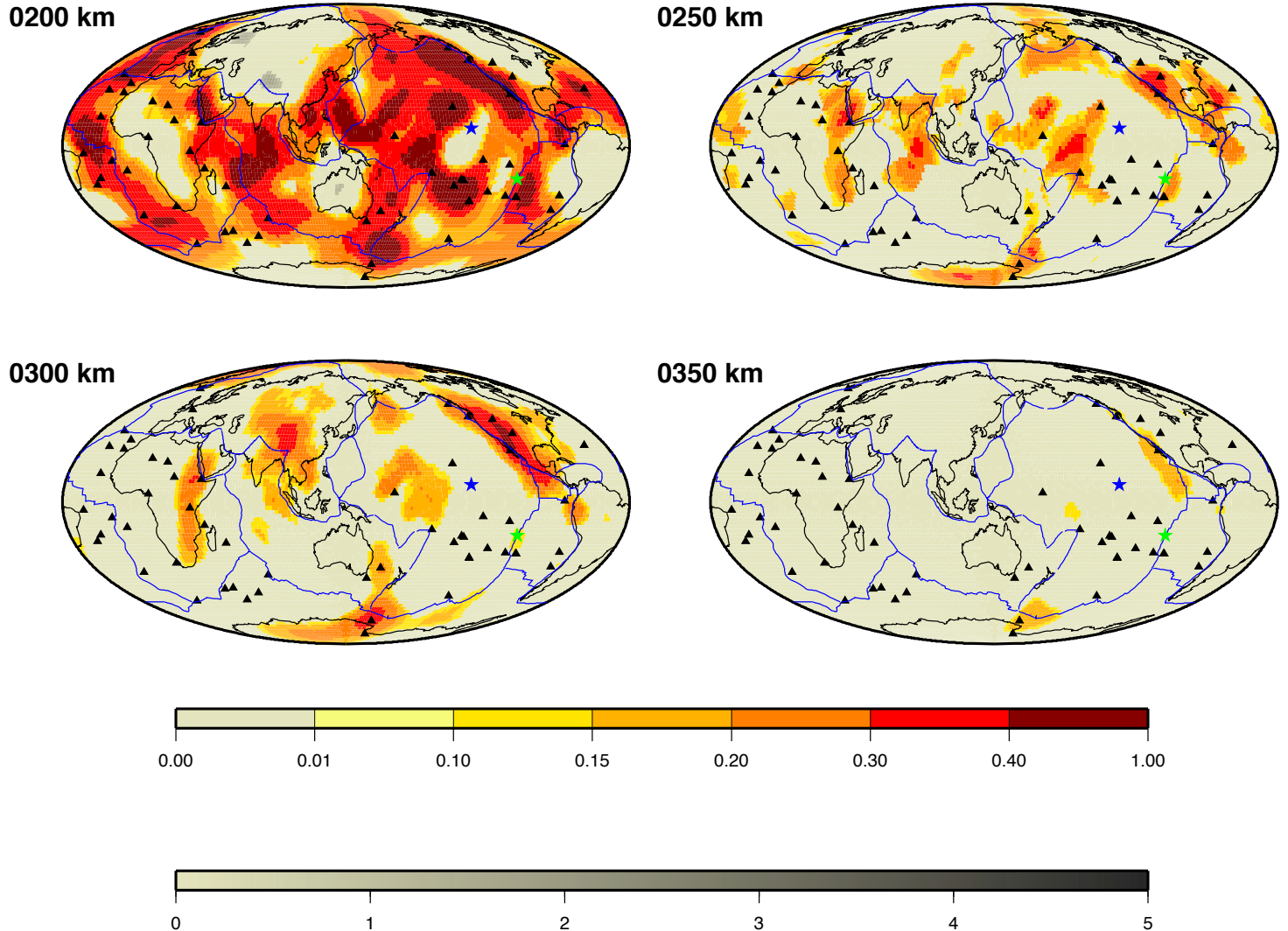

Fig. S4: same as Fig. 3 but using a linear 7.9\% Vs reduction per percent of melt ${ }^{2}$ instead of the polynomial expression derived from experimental results ${ }^{3}$. The upper color scale is slightly modified to allow melt content up to $1 \%$ (the maximum value at $100 \mathrm{~km}$ depth). 

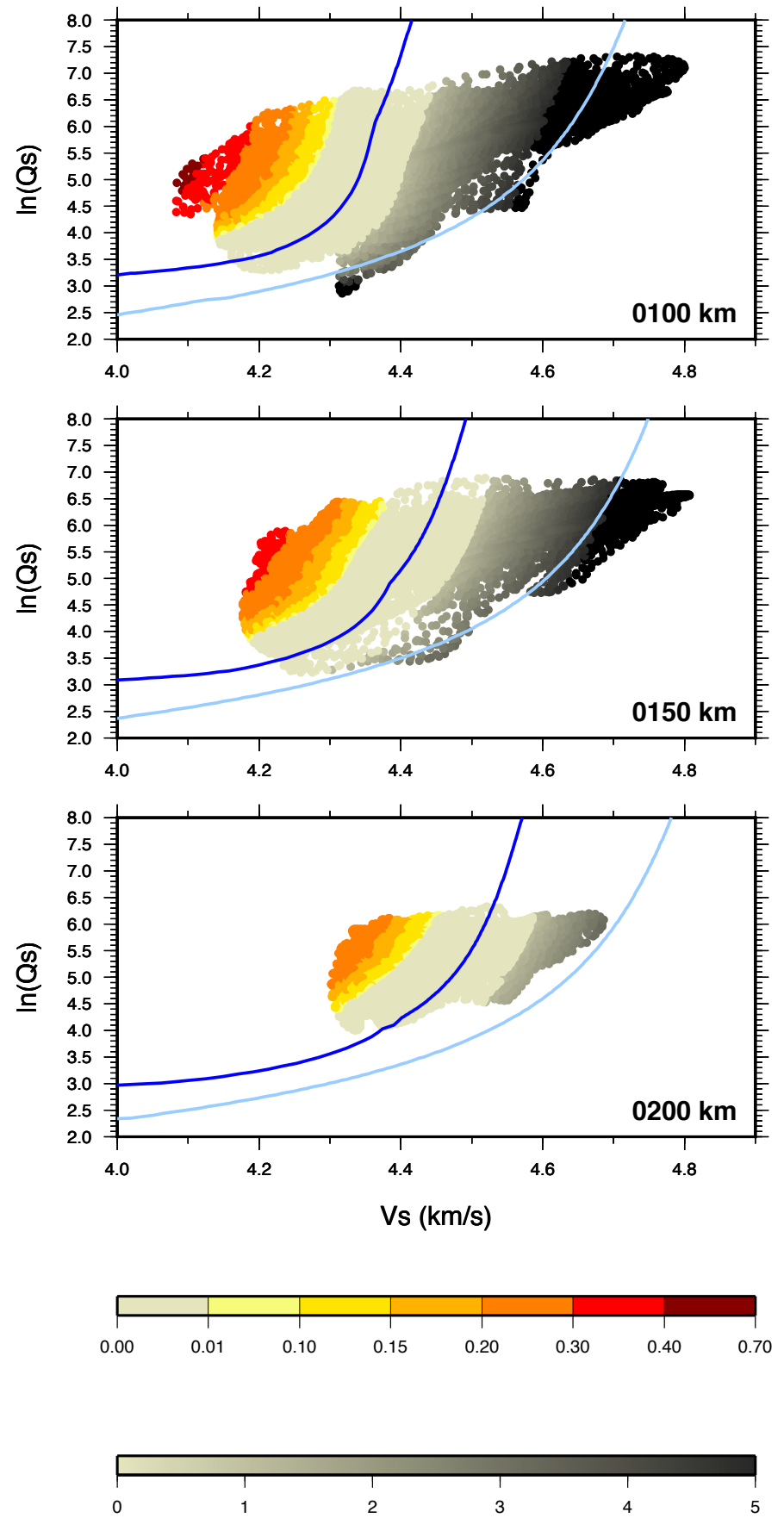

Fig. S5: same as Figure 2 but the unrelaxed shear modulus $\mu_{U}$ needed to compute the temperature-dependent model (dark blue curve) is calculated using parameters proposed for of the temperature model of the Pacific ${ }^{6}$, instead of those deduced from Perple $\mathrm{X}$ assuming a pyrolitic composition. 

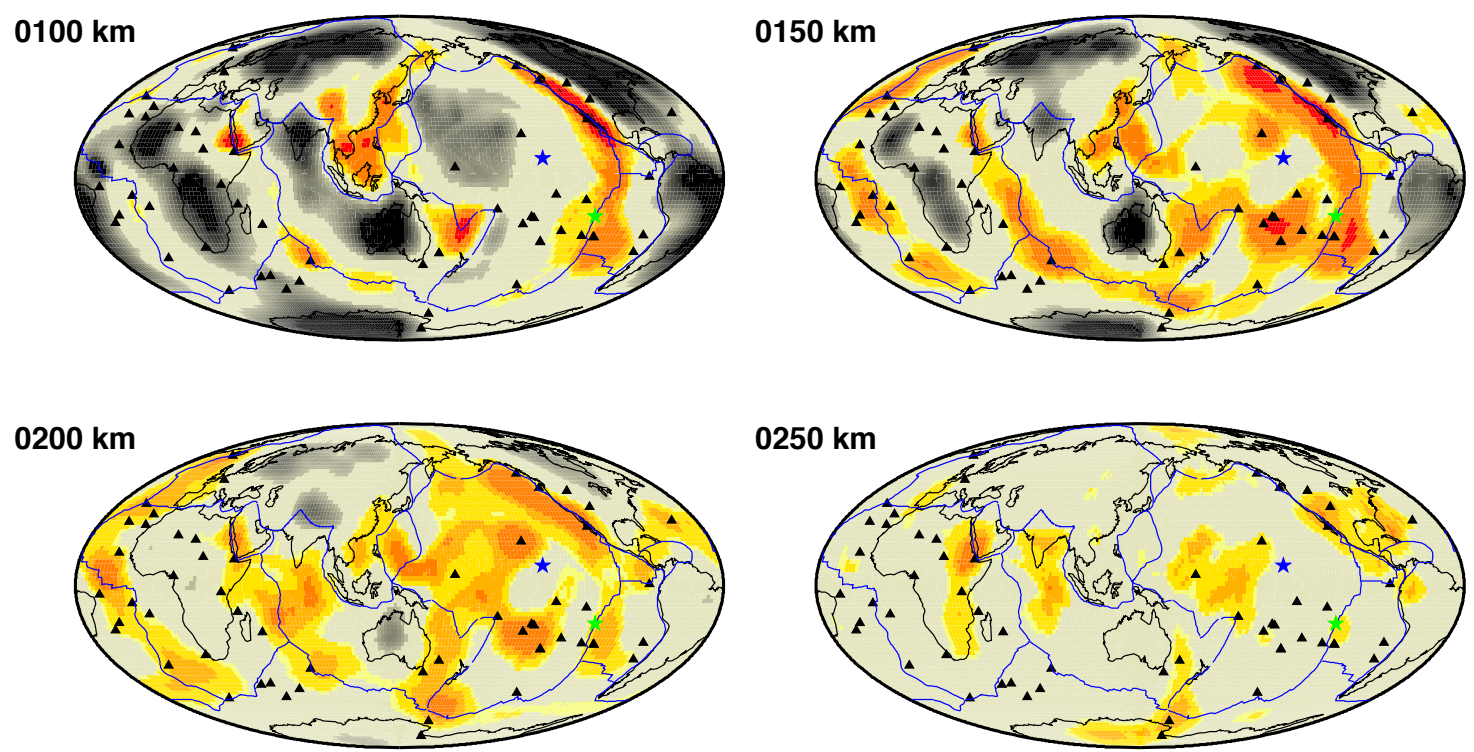

0250 km
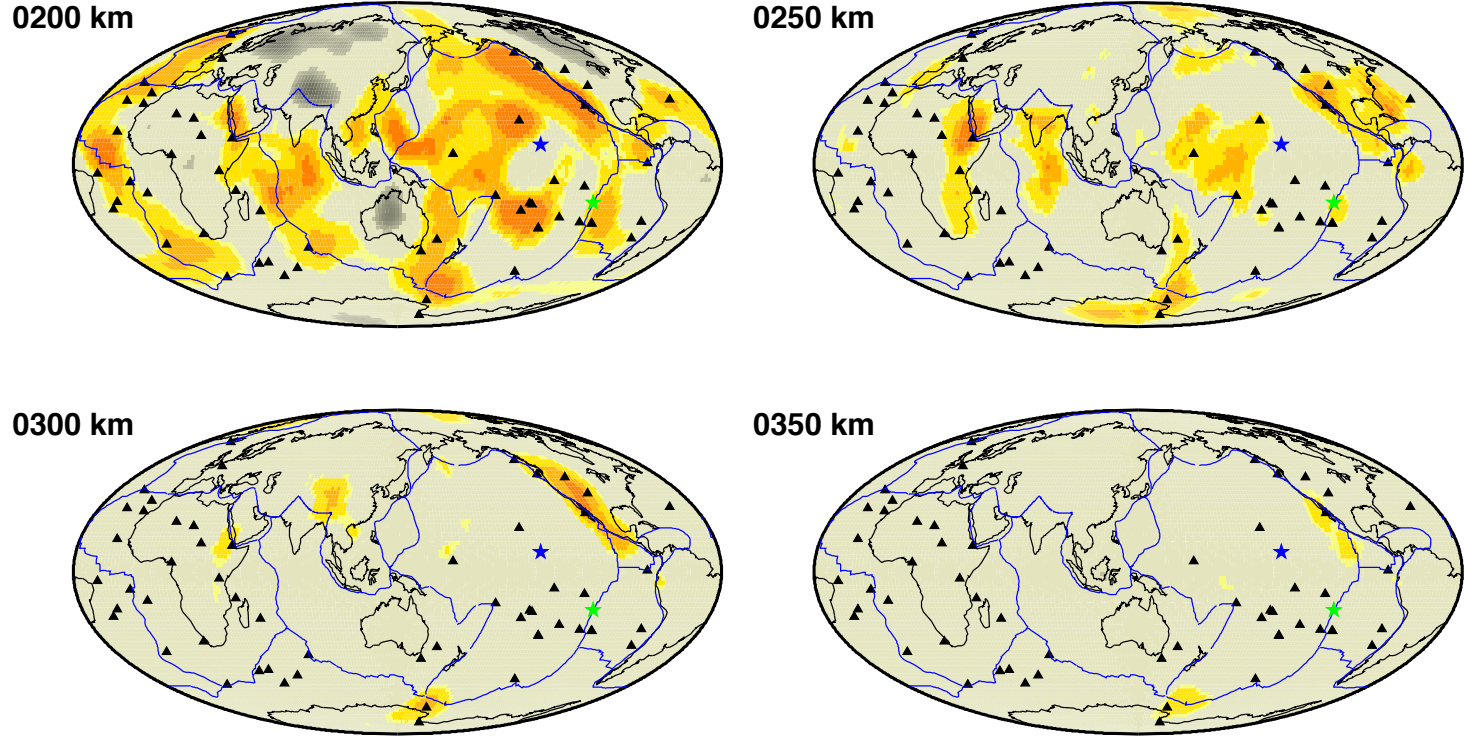

0350 km
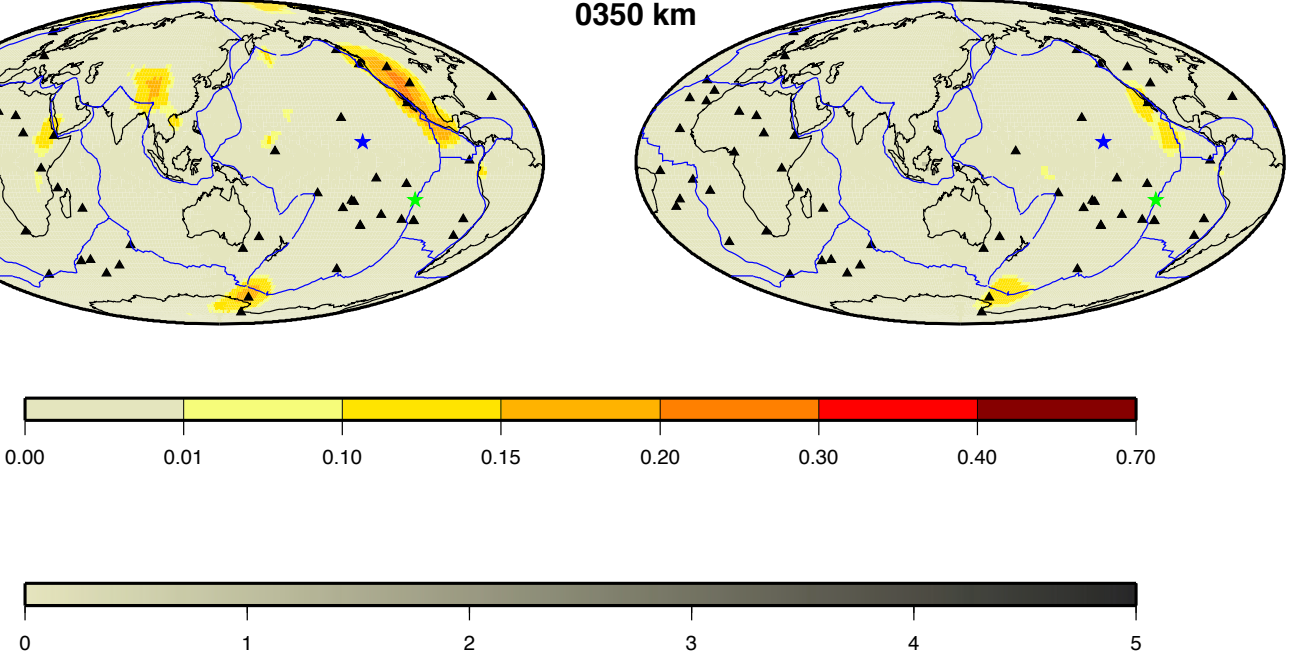

Fig. S6: same as Figure 3 but instead to estimate the unrelaxed shear modulus $\mu_{U}$ using Perple $\mathrm{X}$ and a pyrolitic model, we use fitting parameters of the temperature model for the Pacific ${ }^{6}$. 
$0100 \mathrm{~km}$
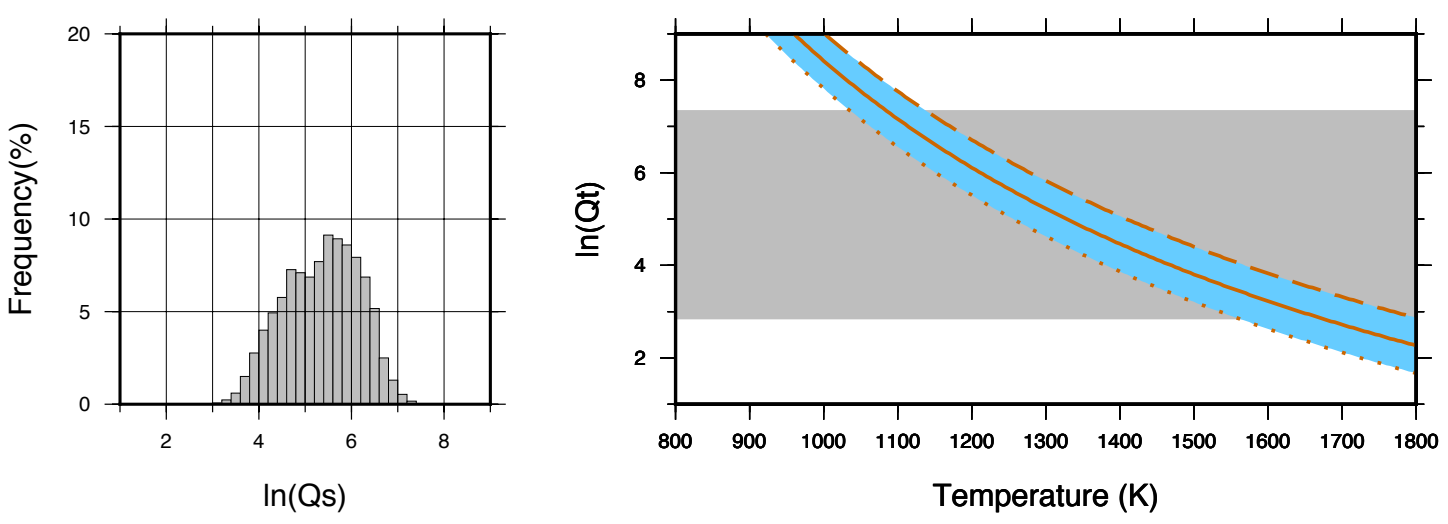

$0150 \mathrm{~km}$
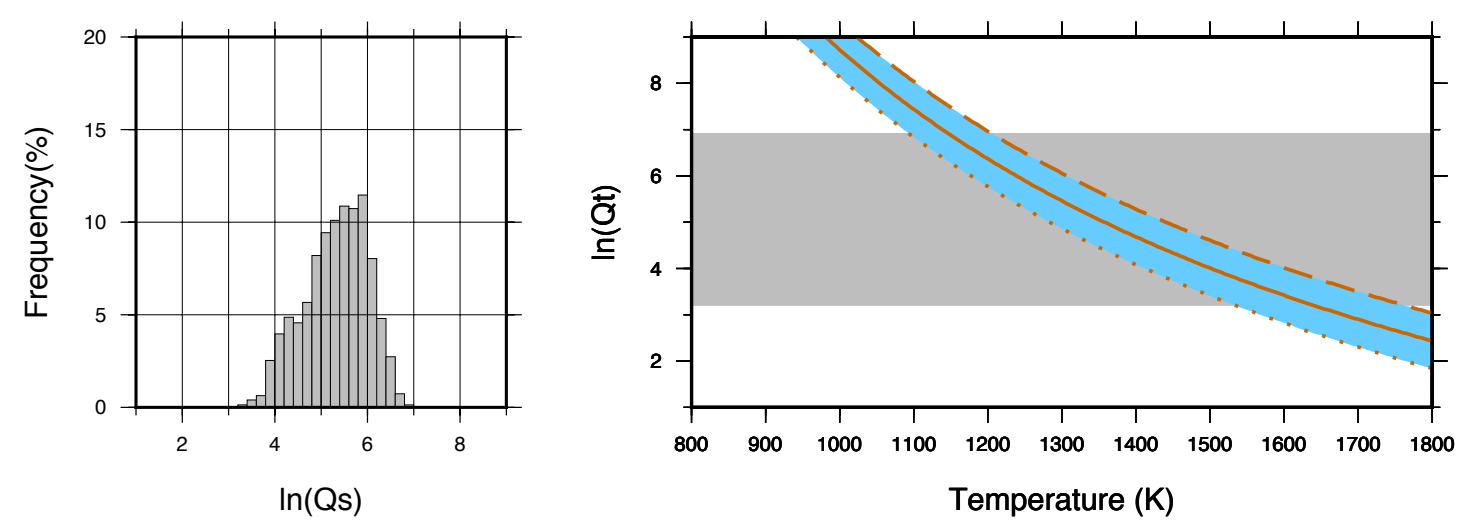

0200 km
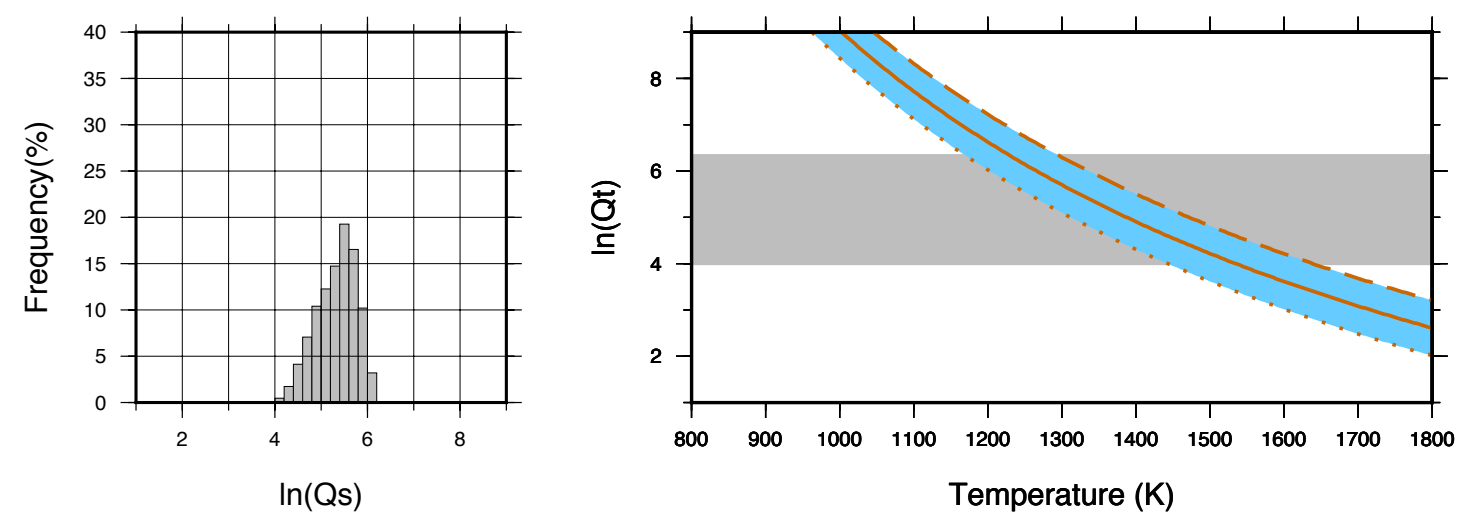

Fig. S7: Left column: Histograms of the distribution of $\ln \left(Q_{s}\right)$ values extracted at 100 (top), 150 (middle) and 200 (bottom) km depth in QsADR177. Right column: at the same depths, theoretical relation between $\ln \left(Q_{t}\right)$ and temperature computed using Eq. A.1 for different grain sizes. The continuous lines in brown are the theoretical curves assuming a grain size of $10 \mathrm{~mm}$. The light blue areas around this curve cover the influence of grain sizes from $1 \mathrm{~mm}$ (bottom dotted curve) to $100 \mathrm{~mm}$ (upper dashed curve). The shaded grey area shows the range of Qs variations observed in QsADR17. 

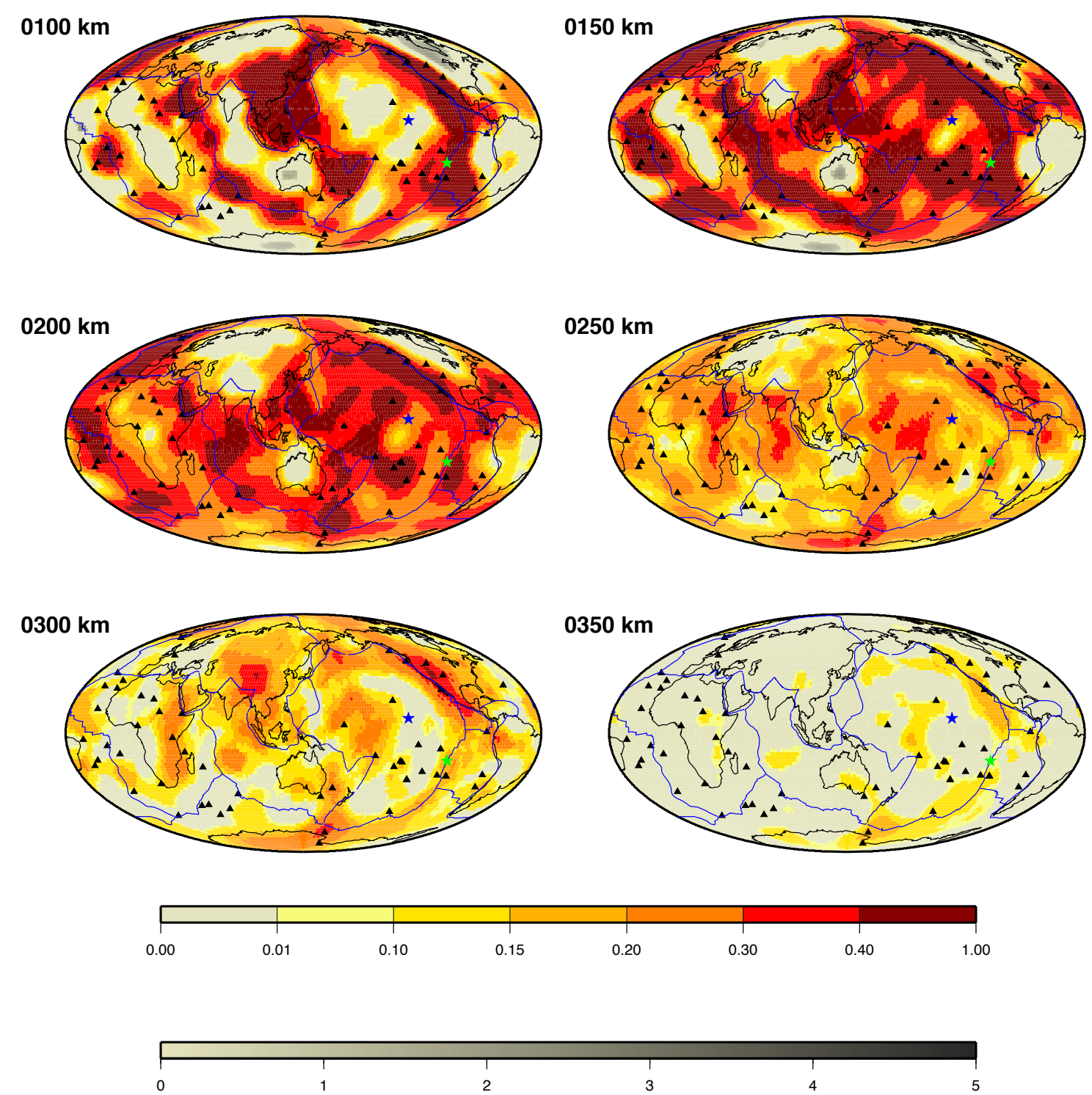

Fig. S8: same as Figure S2 but for a grain size of $100 \mathrm{~mm}$.

\section{References :}

1. Jackson, I., Fitz Gerald, J. D., Faul, U. H. \& Tan, B. H. Grain-size-sensitive seismic wave attenuation in polycrystalline olivine. J. Geophys. Res. Solid Earth 107, 2360 (2002).

2. Hammond, W. C. \& Humphreys, E. D. Upper mantle seismic wave velocity: Effects of realistic partial melt geometries. J. Geophys. Res. Solid Earth 105, 10975-10986 (2000).

3. Chantel, J. et al. Experimental evidence supports mantle partial melting in the asthenosphere. Sci. Adv. 2, (2016).

4. Karato, S. Importance of anelasticity in the interpretation of seismic tomography. Geophys. Res. Lett. 20, 1623-1626 (1993). 
5. Dziewonski, A. M. \& Anderson, D. L. Preliminary reference Earth model. Phys. Earth Planet. Inter. 25, 297-356 (1981).

6. Takei, Y. Effects of Partial Melting on Seismic Velocity and Attenuation: A New Insight from Experiments. in Annual Review of Earth and Planetary Sciences, vol 45 (ed. Jeanloz, R and Freeman, K.) 45, 447-470 (2017).

7. Adenis, A., Debayle, E. \& Ricard, Y. Attenuation tomography of the upper mantle. Geophys. Res. Lett. 44, (2017). 